\title{
Impaired Reliability and Precision of Spiking in Adults But Not Juveniles in a Mouse Model of Fragile X Syndrome
}

Deepanjali Dwivedi, ${ }^{1}$ - Sumantra Chattarji, ${ }^{1,2,3}$ and ${ }^{-}$Upinder S. Bhalla ${ }^{1,2}$

https://doi.org/10.1523/ENEURO.0217-19.2019

${ }^{1}$ National Centre for Biological Sciences, TIFR, Bellary Road, Bangalore 560065, India, ${ }^{2}$ Centre for Brain Development and Repair, Institute for Stem Cell Biology and Regenerative Medicine, Bangalore 560065, India, and ${ }^{3}$ Centre for Discovery Brain Sciences, Deanery of Biomedical Sciences, University of Edinburgh, EH8 9XD Edinburgh, United Kingdom

\section{Visual Abstract}

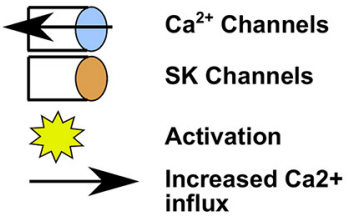

CA3; Low baseline

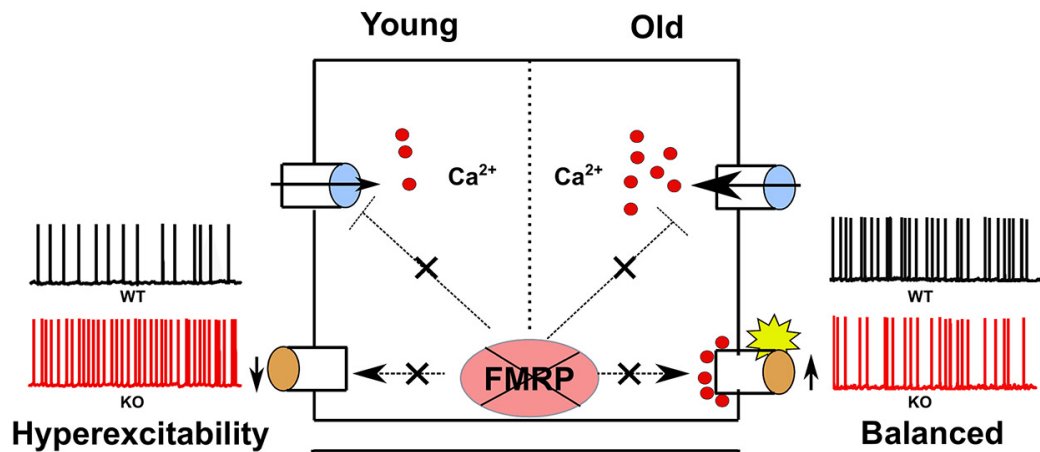

Hyperexcitability
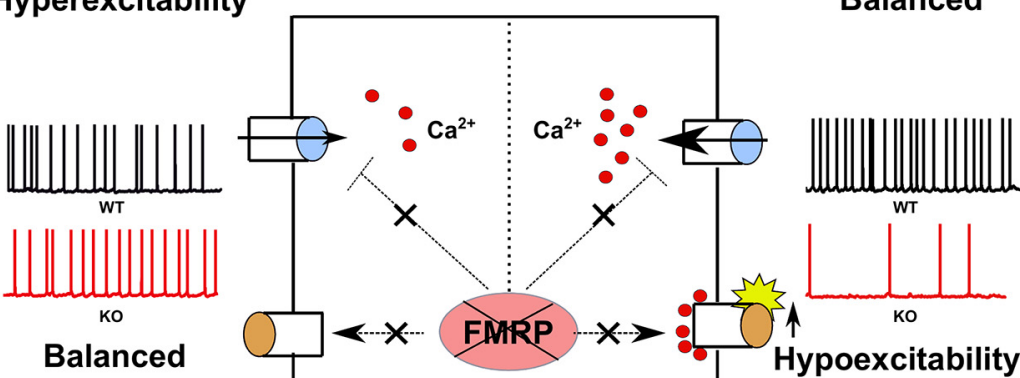

Balanced

Young

Old

CA1; High baseline 


\section{Significance Statement}

Fragile $X$ syndrome leads to a range of intellectual disability effects and autism. We have found a differential effect of FMRP KO in different subsections of hippocampus where it caused an increased spiking in CA3 in juveniles and reduced spiking in CA1, in adults. We have also found that even individual neurons with this mutation exhibit increased variability in their activity patterns. Importantly, this effect emerges after 6 weeks of age in mice. We showed that a specific ion channel protein, the SK channel, was partially responsible, and blockage of these channels led to a partial restoration of cellular activity. This is interesting as it provides a possible molecular link between activity variability in single cells and reported irregularity in network activity.

Fragile X syndrome (FXS) is the most common source of intellectual disability and autism. Extensive studies have been performed on the network and behavioral correlates of the syndrome, but our knowledge about intrinsic conductance changes is still limited. In this study, we show a differential effect of FMRP knockout in different subsections of hippocampus using whole-cell patch clamp in mouse hippocampal slices. We observed no significant change in spike numbers in the CA1 region of hippocampus, but a significant increase in CA3, in juvenile mice. However, in adult mice we see a reduction in spike number in the CA1 with no significant difference in CA3. In addition, we see increased variability in spike numbers in CA1 cells following a variety of steady and modulated current step protocols. This effect emerges in adult mice (8 weeks) but not juvenile mice (4 weeks). This increased spiking variability was correlated with reduced spike number and with elevated AHP. The increased AHP arose from elevated SK currents (small conductance calcium-activated potassium channels), but other currents involved in medium AHP, such as $I_{\mathrm{h}}$ and $\mathrm{M}$, were not significantly different. We obtained a partial rescue of the cellular variability phenotype when we blocked SK current using the specific blocker apamin. Our observations provide a single-cell correlate of the network observations of response variability and loss of synchronization, and suggest that the elevation of SK currents in FXS may provide a partial mechanistic explanation for this difference.

Key words: fragile X syndrome; ion channels; neurodeveloment; SK channels

\section{Introduction}

Fragile $X$ syndrome $(F X S)$ is an autism spectrum disorder arising from increased repeats of CGG trinucleotide in the FMR1 gene. This leads to silencing of the gene and hence to the absence of the FMRP protein (O'Donnell and Warren, 2002). FMRP is a transcription factor that affects multiple downstream genes including ion channels

Received June 6, 2019; accepted October 4, 2019; First published November 4, 2019.

The authors declare no competing financial interests.

Author contributions: D.D., S.C., and U.S.B. designed research; D.D. performed research; D.D., S.C., and U.S.B. contributed unpublished reagents/ analytic tools; D.D. analyzed data; D.D. and U.S.B. wrote the paper.

D.D. was funded by National Centre for Biological Sciences/Tata Institute of Fundamental Research Intramural funds during the project. National Mouse Resource and Department of Biotechnology provided funds for mouse maintenance and experimental equipment.

Acknowledgments: We thank Suranjana Pal, Bishal Basak, Vidya Ramesh, Sarfaraz Nawaz for help with Immunofluorescence experiments. We also thank the National Centre for Biological Sciences Animal Facility and Central Imaging and Flow Cytrometry (CIFF) facility for assisting in animal handling and imaging, respectively. In addition, we thank Giselle Fernandes, Shreya Das Sharma, Aviral Goel, Sathyaa Subramaniyam, Aanchal Bhatia, and Sahil Moza for useful suggestions.

Correspondence should be addressed to Upinder S. Bhalla at Bhalla@ncbs.res.in.

https://doi.org/10.1523/ENEURO.0217-19.2019

Copyright (C) 2019 Dwivedi et al.

This is an open-access article distributed under the terms of the Creative Commons Attribution 4.0 International license, which permits unrestricted use, distribution and reproduction in any medium provided that the original work is properly attributed.
(Brown et al., 2001; Darnell et al., 2011). Studies have shown that the absence of FMRP affects the functioning of ion channels either by regulating the number of channels (Meredith et al., 2007; Strumbos et al., 2010; Gross et al., 2011; Lee et al., 2011a; Routh et al., 2013; Ferron et al., 2014; Zhu et al., 2018) or by directly interacting with the channels (Brown et al., 2010; Deng et al., 2013). Multiple studies have shown that potassium channels have a significant effect on spike precision (Fricker and Miles, 2000; Gittelman, 2006; Cudmore et al., 2010), and many of these potassium channels are transcription hits for FMRP. This leads to the hypothesis that FXS may alter the functioning of one or multiple potassium channels, leading to effects on spike precision.

In recent years a number of in vivo hippocampal recording studies have shown that there is poor correlation of spiking activity between cells, and abnormal theta phasegamma phase coupling in FXS mice (Radwan et al., 2016; Arbab et al., 2018a,b; Talbot et al., 2018). In medial prefrontal cortex, variability in calcium $\left(\mathrm{Ca}^{2+}\right)$ responses has also been observed, leading to impaired spike timing-dependent plasticity (STDP) (Meredith et al., 2007).These studies have led to the "discoordination hypothesis" for FXS (Talbot et al., 2018). This hypothesis states that neurons in FXS are uncorrelated and have aberrant network discharges. In apparent contradiction to this hypothesis, neurons showed hyperconnectivity and synchronization in cortical networks of FXS model mice (Testa-Silva et al., 2012; Gonçalves et al., 2013). 
Synchronicity is an emergent property of a network and is a function of both network connectivity and intrinsic properties. Specifically, potassium conductance has been shown to have significant effects on spike precision and network synchrony (Fricker and Miles, 2000; Pfeuty et al., 2003; Deister et al., 2009; Cudmore et al., 2010; Gastrein et al., 2011; Hou et al., 2012). Modeling studies have also shown that conductance that mediates spike frequency adaptation helps to synchronize network firing (Crook et al., 1998). $I_{\mathrm{h}}$ currents, $I_{\mathrm{M}}$ currents, and SK currents have been shown to mediate adaptation for phase precession in hippocampal neurons, (Orbán et al., 2006; Kwag et al., 2014) spiking reliability in insect neurons (Gabbiani and Dewell, 2018) and also to maintain regular firing in robust nucleus of acropallium in zebra finches (Hou et al., 2012). Thus FXS mutations, through their effects on potassium channels, may lead to several of the observed network dysfunctions in FXS models.

In the present study, we tested alterations in intrinsic properties of the cell that might underlie the above network observations of uncorrelated activity. First, we observed that cells from FXS knock-out (KO) hippocampal slices were more unreliable, both at within-cell and between-cell levels, than controls. Consistent with the developmental manifestations of FXS, this effect was absent in juvenile mice and emerged only after $\sim 6$ weeks. Decreased spiking in $\mathrm{KO}$ mice was correlated with increased variability. At the mechanistic level, we found that the spiking changes were due to elevated medium afterhyperpolarization (mAHP), which in turn was due to elevated SK currents. In contrast to these observations of decreased spiking in the CA1 region of adult animals, we observed increased spiking in the CA3 region of juvenile animals (Deng et al., 2019), but not in the CA1 region. Consistent with earlier observations (Deng et al., 2019), we did not see any significant change in the spatial distribution of SK channels in either CA3 or CA1. Finally, we tested the outcome of the blockers of SK and found that that they indeed led to a partial rescue of the observed phenotype of increased spiking variability and reduced timing precision in adult animals.

\section{Materials and Methods}

\section{Animals}

C57BL/6 strain of Fmr1tmCgr male mice were used for the experiments. All experimental procedures were approved by the National Centre for Biological Sciences ethics committee [Project ID: NCBS-IAE-2017/04(N)]. The animals were housed in the institute animal house where they were maintained on a $12 \mathrm{~h}$ light/dark cycle. The animals used were from an older animal group in the range of 6-8 weeks of age; the younger group was 3-4 weeks of age.

\section{Slice preparation}

Mice were anesthetized with halothane. Their head was decapitated after they were killed by cervical dislocation. Hippocampal slices were made in the ice-cold aCSF of the following composition: $115 \mathrm{~mm} \mathrm{NaCl}, 25 \mathrm{~mm}$ glucose, $25.5 \mathrm{~mm} \mathrm{NaHCO}_{3}, 1.05 \mathrm{~mm} \mathrm{NaH}_{2} \mathrm{PO}_{4}, 3.3 \mathrm{~mm} \mathrm{KCl}, 2 \mathrm{~mm}$
$\mathrm{CaCl}_{2}$, and $1 \mathrm{~mm} \mathrm{MgCl}$. $400-\mu \mathrm{m}$-thick slices were made using a VT1200S vibratome and then incubated at room temperature for $1 \mathrm{~h}$ in the aCSF, which was constantly bubbled with $95 \% \mathrm{O}_{2}$ and $5 \% \mathrm{CO}_{2}$. Subsequently, the slices were transferred to the recording chamber where they were maintained at an elevated temperature of $30-$ $34^{\circ} \mathrm{C}$ for the recordings.

\section{Electrophysiology}

CA1 neurons were identified under an upright differential interference contrast microscope (BX1WI microscope, Olympus) using a $40 \times$ objective (water immersion lens, 0.9 numerical aperture, LUMPLFLN, 40×). 2-4 M $\Omega$ pipettes were pulled from thick-walled borosilicate glass capillaries on a P-1000 Flaming Micropipette Puller (Sutter Instrument). The pipettes were filled with internal solution of the following composition for whole-cell currentclamp recordings: $120 \mathrm{~mm}$ potassium gluconate, $20 \mathrm{~mm}$ $\mathrm{KCl}, 0.2 \mathrm{~mm}$ EGTA, $4 \mathrm{~mm} \mathrm{NaCl}, 10 \mathrm{~mm}$ HEPES buffer, 10 $\mathrm{mm}$ phosphocreatine, $4 \mathrm{~mm} \mathrm{Mg}$-ATP, and $0.3 \mathrm{~mm} \mathrm{Na}$-GTP, at (pH 7.4 and $295 \mathrm{mOsm})$. For voltage-clamp recordings, the same composition of internal solution was used with the one change: $120 \mathrm{~mm}$ potassium gluconate was substituted with $120 \mathrm{~mm}$ potassium methylsulphate. Cells were recorded if they had a resting potential of $\leq 60 \mathrm{mV}$. We also required that they exhibit stable firing with little or no depolarization block for lower current inputs. Series resistance and input resistance were continuously monitored during the protocols, and the cell was discarded if these parameters changed by $>25 \%$.

\section{Protocol for measuring spike variability and analysis}

All spike variability and precision experiments were performed in current-clamp mode. A step input current stimulus of 150 pA DC for 900 ms was used for the majority of the recordings. In some cases, as indicated in the text, frozen noise and sinusoidal input currents were also used, riding on a baseline current step of $150 \mathrm{pA}$, and again for a duration of $900 \mathrm{~ms}$. The SDs of noise used in noise protocols were $10,25,50$, and $100 \mathrm{pA}$ with a time cutoff of $\tau=3 \mathrm{~ms}$. For sinusoidal currents, SDs of 50 and $100 \mathrm{pA}$ were used at $5 \mathrm{~Hz}$. All the protocols were repeated for 25 trials. Within-cell spike variability $\left(\mathrm{CV}_{w}\right)$ was computed as coefficient of variation (CV) in spike numbers across 25 trials. Spike numbers computed for all 25 trials were used to find the SD in spike numbers, which was then divided by the mean number of spikes to find $\mathrm{CV}_{w}$, as follows:

$$
\left(\mathrm{CV}_{\mathrm{w}}\right)_{\mathrm{n}}=\sigma_{\mathrm{n}} / \mu_{\mathrm{n}}
$$

where $n$ is the cell index, $\sigma_{n}$ is the SD across trials within cell $n$, and $\mu_{n}$ is the mean number of spikes across all the trials within cell $n$.

The array of floating point numbers (i.e., vector for $C_{w}$ ) was computed for all recorded KO and wild-type (WT) cells, respectively, and was used for comparing the responses (Fig. 1E). The distributions in $\mathrm{CV}_{w}$ were compared using the Wilcoxon test.

The analysis of between-cell spiking variability $\left(\mathrm{CV}_{b}\right)$ was derived from an article that reports experiments on 
A

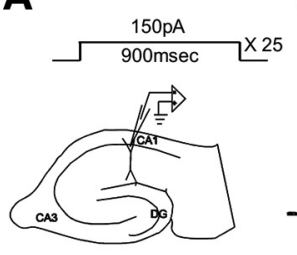

c
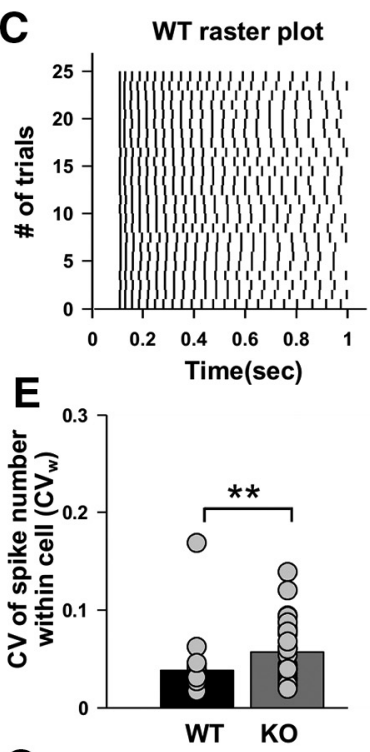

G

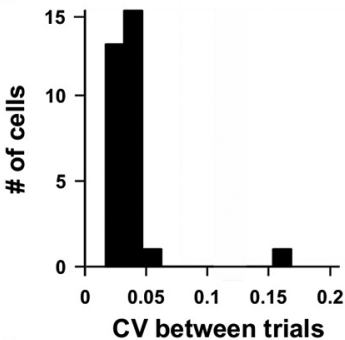

I WT
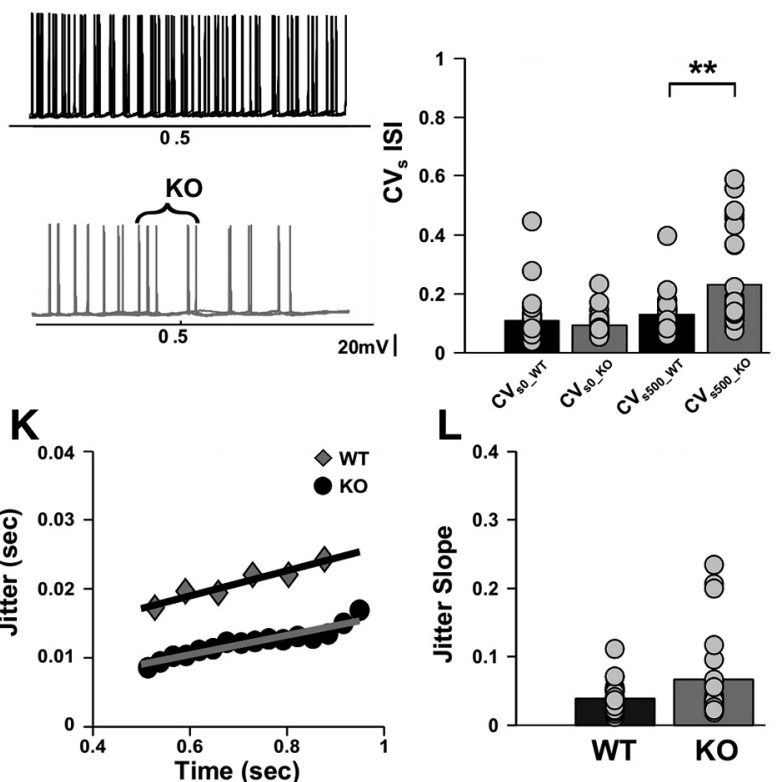

Figure 1. Increased spike variability and spike timing imprecision
Figure 1. continued

both at the within-cell level (Co-efficient of Variation - $\mathrm{CV}_{w}$ ) across multiple trials and between cells (Co-efficient of Variation - $\mathrm{CV}_{b}$ ) in CA1 hippocampus of FXS animals. $\boldsymbol{A}$, Schematic of a hippocampal slice and the step depolarization protocol. The protocol consists of a 150 pA step for $900 \mathrm{~ms}$ time duration repeated over 25 trials. $\boldsymbol{B}$, Representative raw traces of spiking, superimposed for four trials only for WT (black) and KO (gray). Calibration: 20 mV, 200 ms. C, $\boldsymbol{D}$, Representative raster plot showing spiking for the step depolarization protocol for WT (black; C) and KO (gray; $\boldsymbol{D}$ ). $\boldsymbol{E}$, Bar plot for within-cell variability across multiple trials $\left(\mathrm{CV}_{w}\right)$ for WT $(n=30$ cells, black) and KO ( $n=29$ cells, gray). KO cells have significantly higher within-cell variability than WT cells $(p=0.0048$, Wilcoxon rank sum test). $\boldsymbol{F}$, Bar plot for between-cell variability $\left(\mathrm{CV}_{b}\right)$ for matched trials, WT ( $n=30$ cells, black) and KO ( $n=29$ cells, gray). $\mathrm{KO}$ cells have significantly higher between cell variability than WT cells ( $p<0.001$, Wilcoxon rank sum test). $\boldsymbol{G}, \boldsymbol{H}$, Histogram showing the spread of the $\mathrm{CV}_{w}$ parameter for WT ( $n=30$ cells, black; $\boldsymbol{G}$ ) and for KO ( $n=29$ cells, gray; $\boldsymbol{H})$. KO cells have more spread in $\mathrm{CV}_{w}$ parameter, depicting heterogeneity in $\mathrm{KO}$ cell population. I, Representative trace showing the time window where $\mathrm{CV}_{\mathrm{s}}$ in ISI is calculated for WT (top, black trace) and for KO (bottom, gray trace). Superimposed traces are for four trials only. A curly bracket in the $\mathrm{KO}$ trace shows the time window in which $\mathrm{CV}_{s 500}$ is calculated. Calibration: $20 \mathrm{mV}$. J, Bar plot for $\mathrm{CV}_{\mathrm{s}}$ in ISI, a measure of spike precision for WT ( $n=30$ cells, black) and KO ( $n=29$ cells, gray). $\mathrm{CV}_{s 0}$ is not significantly different between $\mathrm{WT}$ and $\mathrm{KO}$. However, there is a significant increase in the $\mathrm{CV}_{s 500}$ for $\mathrm{KO}$ cells compared with WT ( $p=0.018$ for WT vs KO differences; two-way ANOVA). $K$, Representative trace showing jitter in spike timings for one WT cell (black circles) and one KO cell (gray diamonds). The straight line is a regression fit to the points, and its slope is a measure of the increase in jitter with time. Jitter in spike timings are calculated only for the last $400 \mathrm{~ms}$ of the trial. $L$, Bar plot for jitter slope, a measure of spike precision for WT $(n=29$ cells, black) and KO ( $n=23$ cells, gray). The jitter slope is not significantly different between WT and KO cells $(p=0.14$; Wilcoxon rank sum test). $* * * p<0.001, * * p<0.01$.

network synchrony (Talbot et al., 2018). In contrast to our $\mathrm{CV}_{w}$ analysis, where variability in spiking was assessed within each cell, $\mathrm{CV}_{b}$ measures the variability across trials between cells. For computing $\mathrm{CV}_{b}$, spike numbers on corresponding trial numbers were compared between different cells. Specifically, we constructed a vector for each cell whose entries were the number of spikes for successive trials. These vectors were compared across different cells within the same genotype and were used to find $\mathrm{CV}_{b}$. The following formula was used for the computation:

$$
\left(\mathrm{CV}_{\mathrm{b}}\right)_{\mathrm{i}}=\sigma_{\mathrm{i}} / \mu_{\mathrm{i}},
$$

where $i$ is the trial index, $\sigma_{\mathrm{i}}$ is the SD over trial $i$ between cells, and $\mu_{i}$ is the mean number of spikes on trial $i$ between all cells. The $\mathrm{CV}_{b}$ vectors were computed for WT and $\mathrm{KO}$ populations, respectively (Fig. 1F), and compared using Wilcoxon statistics.

\section{Measurement of spike timing precision}

Measurement of spike timing precision: $\mathrm{CV}_{\mathrm{s}}$

Spike times were calculated for all the spikes in all trials. The interspike interval (ISI) was computed for the first two spikes and for spikes that bracketed a time of $500 \mathrm{~ms}$ after the start of the step input protocol (Fig. 1/). For each 
cell $m$, we obtained the coefficient of variation, $\mathrm{CV}_{s 0 m}$ and $\mathrm{CV}_{\mathrm{s} 500 \mathrm{~m}}$ for the first ISI and the ISI at $500 \mathrm{~ms}$, respectively, as follows:

$$
\mathrm{CV}_{\mathrm{s} 0-\mathrm{m}}=\sigma_{0 \mathrm{~m}} / \mu_{0 \mathrm{~m}},
$$

where $m$ is the cell index, $\sigma_{m}$ is the SD of ISI across trials within cell $m$, and $\mu_{m}$ is the mean ISI across all the trials for cell $m$. We calculated $\mathrm{CV}_{s 500 \_m}$ in a similar manner.

By repeating this calculation over all cells, we obtained the following four vectors: $\mathrm{CV}_{\text {so_wT }}, \mathrm{CV}_{\text {s50o_wT }}, \mathrm{CV}_{\text {so_ko, }}$ and $\mathrm{CV}_{5500 \mathrm{KO}}$. The distributions in these four vectors were compared using a two-way ANOVA (Fig. 1J).

\section{Jitter slope}

The jitter slope analysis was taken from the study by Bacci and Huguenard (2006). Jitter was defined as $\sigma_{t i}$, which is the SD of spike timing for spike number $i$, compared over all trials for a given cell. In this manner, the vector $\sigma_{t}$ was obtained by considering all the spike numbers. Note that not all trials had the same number of spikes, so the final few spike numbers may have had fewer samples in $\sigma_{t}$.

The jitter slope was obtained as a regression fit for the vector $\sigma_{t}$, with the $x$-axis defined by the corresponding vector for mean timings $\mu_{t}$. This slope was calculated for spikes falling in the last $400 \mathrm{~ms}$ of the current pulse since this is where the SK channel is activated. As a pre hoc criterion, cells were required to have a minimum of two spike time points to be selected for this calculation. Note that this criterion excluded several cells that had strong suppression of firing toward the end of the trial, presumably due to SK channel activation. Thus, this measure was compromised by being insensitive to precisely those cells with the largest effects in the KO.

\section{Measurement of frequency versus current curves}

The measurement of frequency versus current ( $f-l)$ curves was performed in current clamp. For plotting $f-I$ curves, each cell was given input currents from -100 to $400 \mathrm{pA}$ at its resting membrane potential (RMP). The mean \pm SEM of the number of spikes elicited for each input current was plotted on the $y$-axis, and the corresponding input current on the $x$-axis.

\section{AHP measurement}

AHPs were measured by holding the cell at $-70 \mathrm{mV}$ in current-clamp mode, using some holding current. In each trial, the holding current was set to 0 for $200 \mathrm{~ms}$, and then step input for $100 \mathrm{~ms}$ was delivered. The current during this step input was adjusted so that the cell produced five spikes in $100 \mathrm{~ms}$. This stimulus was repeated for 15 trials, and the voltage traces of all the trials were averaged. AHPs were analyzed as the hyperpolarization after the spike train. mAHP was computed as the average hyperpolarization $50 \mathrm{~ms}$ after the spike train, and slow AHP (sAHP) was computed $200 \mathrm{~ms}$ after the spike train (see Fig. $5 A, B)$.

\section{Immunofluorescence experiments and analysis}

The 3- to 4-week-old or 6- to 8-week-old animals were anesthetized, and brains were dissected out. Brains were fixed in $4 \%$ PFA for $48 \mathrm{~h}$ at $4^{\circ} \mathrm{C}$. Postfixation, brains were washed with PBS, and $30-\mu \mathrm{m}$-thick slices were cut on a VT12000S vibratome. Slices were kept in cryoprotectant solution and stored at $-20^{\circ} \mathrm{C}$ for further use. Slices were resuspended in PBS solution for the experiment. $50 \mathrm{mM}$ ammonium chloride $\left(\mathrm{NH}_{4} \mathrm{Cl}\right)$ was used to quench autofluorescence from the samples. After multiple steps of washing and permeabilization in $0.3 \%$ PBS with Triton X-100, cells were incubated with $5 \%$ normal goat serum (NGS) for blocking for 1-2 h. Followed by washes, slices were incubated in primary antibody for the SK2 channel, overnight at $4^{\circ} \mathrm{C}$. Primary antibody was purchased from Alomone Labs (catalog \#APC-028) and were used in 1:300 dilution with 2.5\% NGS. Further, slices were incubated in secondary antibody at 1:500 dilution for 1-2 $\mathrm{h}$ at room temperature. After several washes and DAPI staining (Sigma-Aldrich) for $15 \mathrm{~min}$ in PBS, slices were mounted in Prolong Gold Mounting Media and imaged with an Olympus FV3000 confocal microscope.

\section{Measurement of $M$ and $I_{h}$ currents}

For measuring the $I_{\mathrm{h}}$ sag produced in voltage change, cells were held at $-70 \mathrm{mV}$ and given a step hyperpolarization of $250 \mathrm{pA}$ for $500 \mathrm{~ms}$ in current-clamp mode. Voltage deflection was calculated by finding the percentage change between maximum and steady-state voltages during the hyperpolarizing pulse $\left[\left(V_{\max }-V_{\mathrm{ss}}\right) / V_{\max }\right] * 100$. Each cell was presented with 15 trials, and $I_{\mathrm{h}}$ sag was averaged across all the trials to get a value for a cell.

TTX $(0.5 \mu \mathrm{M})$ was added in the bath while measuring $\mathrm{M}$ currents in voltage clamp. For measuring $\mathrm{M}$ currents, cells were held at $-20 \mathrm{mV}$, and $\mathrm{M}$ currents were deactivated in steps from -20 to $-80 \mathrm{mV}$ with a difference of $10 \mathrm{mV}$ in a $900 \mathrm{~ms}$ time duration. The difference between the steady-state current after the start of the protocol (from the last $250 \mathrm{~ms}$ ) and the baseline of the cell was quantified as the current elicited due to the protocol. Specific M current blocker XE991 (30 $\mu \mathrm{M})$ was perfused to get the postblocker trace. The difference between pre- and postXE991 perfusion was quantified as the $M$ current.

\section{Measurement of SK currents}

TTX $(0.5 \mu \mathrm{M})$ was added into the bath while measuring SK currents in voltage clamp. For measuring SK currents, cells were held at $-55 \mathrm{mV}$ while increasing voltage steps were given from -55 to $+35 \mathrm{mV}$, in increments of $10 \mathrm{mV}$, for 800 ms duration. Each voltage step was preceded with a small hyperpolarization from -55 to $-65 \mathrm{mV}$ for $100 \mathrm{~ms}$. Cell capacitance compensation was performed during the recordings. The SK currents were estimated from the amplitude of the outward current $25 \mathrm{~ms}$ after the voltage was returned to the holding potential as the initial part of the trace will be contaminated with capacitance currents (see Fig. $6 A, B)$. Apamin perfusion (100 nM) was performed to identify these currents. The same protocol was used post-apamin perfusion. The difference in current between pre-apamin and post-apamin perfusion was quantified to find the apamin-sensitive SK current. 


\section{Data acquisition and analysis}

Recordings were performed using an Axopatch 200 B Amplifier and digitized using a Digidata 1400A digitizer. Current-clamp recordings were filtered at $10 \mathrm{kHz}$ and sampled at $20 \mathrm{kHz}$. Voltage-clamp recordings were conducted at a gain of 5 , filtered at $3 \mathrm{kHz}$, and sampled at 20 $\mathrm{kHz}$. All analyses were performed using custom-written code in MATLAB (R2013a) and GraphPad Prism 6. Statistical tests were performed after checking the normality of the data. We plotted the data to check for normality. Even if the data looked normal, a Wilcoxon rank sum test was used for most analysis for more stringent results. For multiple comparisons, ANOVA was used with Sidak's post hoc test or $t$ test with Bonferroni correction as post hoc tests. All data are plotted as the mean \pm SEM.

\section{Drugs and chemicals used}

All toxins were purchased from Sigma-Aldrich except for TTX, which was from Hello Bio. TTX (stock solution of $0.5 \mathrm{~mm}$ ) and apamin (stock solution of $1 \mathrm{~mm}$ ) were made with Milli-Q water. XE991 (stock solution of $10 \mathrm{~mm}$ ) was made in DMSO. All stocks were stored at $-20^{\circ} \mathrm{C}$ and were diluted to the working concentration immediately before the experiments.

\section{Experiment design and statistical analysis}

We have used hippocampal slice preparation from male mice in this study, where CA1 and CA 3 regions were used for electrical recordings. Different current inputs were injected into the cell soma via recording electrode, and elicited spikes were recorded in current-clamp mode. Spiking variability was assessed by finding the CV for within a cell and between cells. Spike precision was assessed by comparing CV ISI occurring in the initial part of the trail with the ISI occurring around $500 \mathrm{~ms}$ post commencement of the trial. SK currents were measured in voltage-clamp mode and were found to be partially responsible for increased variability. In addition, we found a differential effect of FMRP KO in different subsections of hippocampus. In young animals, we observed KOs having hyperexcitability for CA3 cells with no difference in CA1 cells. In older animals, we saw that the hyperexcitability seen in CA3 goes away while there is an emergence of hypoexcitability in CA1 cells. All analysis and plotting was performed in MATLAB and GraphPad 6. The normality of the data was checked by plotting it. Even if the distribution followed a normal distribution profile, a Wilcoxon test was used. For multiple comparisons, two-way or threeway ANOVA with Sidak's post hoc test or $t$ test using a Bonferroni correction were used as the post hoc test.

\section{Results}

\section{FMR1 KO cells exhibit increased variability in spike numbers and impaired spike precision}

We performed whole-cell patch clamp recordings in brain slices from CA1 cells of dorsal hippocampus in male WT and KO littermate animals (6-8 weeks old). Somatic current injection was used to inject various waveforms of current (Fig. 1A). These included a square current step, frozen noise riding on a current step, and a sinusoidal wave form riding on a current step (Fig. 2). In each case, we measured the variability in spiking over the $900 \mathrm{~ms}$ of current injection, in the following two respects: first, the variability within a neuron, over repeated trials $\left(\mathrm{CV}_{w}\right)$; and, second, the variability between neurons, comparing matching trials between cells $\left(\mathrm{CV}_{b}\right.$; see Materials and Methods).

We computed the co-efficient of variation $\left(\mathrm{CV}_{w}\right)$ of spike numbers for each of the current stimulus protocols (see Materials and Methods). We observed that the CV of spike numbers across trials within cells $\left(\mathrm{CV}_{w}\right)$ was significantly higher for KO cells compared with WT cells, but only for the step current protocol $\left(\mathrm{CV}_{w}\right.$ for WT, $0.038 \pm 0.005, n=$ 30 cells; $\mathrm{CV}_{w}$ for $\mathrm{KO}, 0.057 \pm 0.006, n=29$ cells; $p=$ 0.0048 ; Wilcoxon rank sum test; Fig. $1 B-D$ ). For other protocols, where frozen current noise or sinusoidal waveforms were riding on top of a current pulse, spikes were very reliable over different trials for both WTs and KOs (Fig. 2A-E). We then estimated the variability between cells $\left(\mathrm{CV}_{b}\right)$. To do this, we compared spike numbers between different WT and KO cells by matching corresponding trials, such that we compared spiking between the first trials of WT between all the WT cells, second trials of WT between all cells, and so on forth, within the same genotype. Similar comparisons were made for KO cells as well (see Materials and Methods). From this procedure, we found that between-cell variability was significantly elevated in KO cells compared with WT cells $\left(\mathrm{CV}_{b}\right.$ for WT cells, $0.29 \pm 0.003, n=30$ cells; $\mathrm{CV}_{b}$ for KO cells, $0.41 \pm$ $0.002, n=29$ cells; $p<0.001$; Wilcoxon rank sum test; Fig. 1F). We plotted the $\mathrm{CV}_{w}$ of spike numbers within the cell for WT and KO populations and observed that KOs have a much wider spread compared with WT (SD of the $\mathrm{CV}_{w}$ population for WT cells $=0.026, n=30$ cells; SD of the $\mathrm{CV}_{w}$ population for $\mathrm{KO}$ cells $=0.03, n=29$ cells; Fig. $1 G, H)$. This implied that $\mathrm{KO}$ cells have a more heterogeneous population than WT cells. In KO mice, some cells were reliable (i.e., they produced a similar number of spikes across multiple trials but some did not). Based on this analysis (Fig. $1 G, H$ ), we found that $51.7 \%$ of $K O$ cells had $\mathrm{CV}_{w}$ values that did not overlap with those of WT cells.

Spike timing precision was computed by finding $\mathrm{CV}_{s}$ in ISIs (Materials and Methods) and by jitter slope analysis (Materials and Methods). We compared $\mathrm{CV}_{s 0}$ with $\mathrm{CV}_{s 500}$ to assess the contribution of SK channels, which are shut at $t=0$, but open by $t=500$. We chose not to use the last ISI for this comparison because the timing of the last spike was very variable in $\mathrm{KO}$ cells. We then compared $\mathrm{CV}_{s}$ at $t=0$ and $t=500$, between WT and $\mathrm{KO}$ cells using two-way ANOVA. We found that there was no significant difference between WT and KO cells for $\mathrm{CV}_{s 0}$. However, at $t=500$, we found that $\mathrm{CV}_{\text {s500_ko }}$ was significantly elevated compared with $\mathrm{CV}_{\text {s500_wT }}\left(\mathrm{CV}_{\text {so_wT }}=0.11 \pm 0.014\right.$; $\mathrm{CV}_{\text {so_kO }}=0.09 \pm 0.007 ; \mathrm{CV}_{\text {s500_WT }}=0.13 \pm 0.01$; $\mathrm{CV}_{\text {s500_KO }}=0.23 \pm 0.03 ; F_{(1,113)}=5.78 ; p=0.018$ for WT versus KO differences; two-way ANOVA, $t$ test with Bonferroni corrections; Fig. 1J). The jitter slope analysis did not report a significant difference in spike imprecision between WT and KO. We used the last $400 \mathrm{~ms}$ of the trial 
A

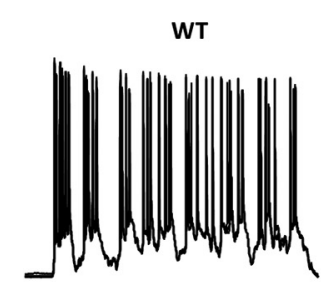

B

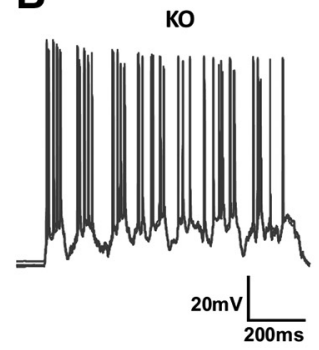

C

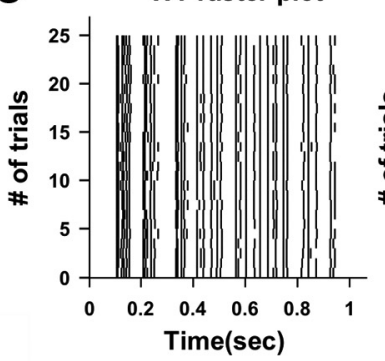

D Ko raster plot

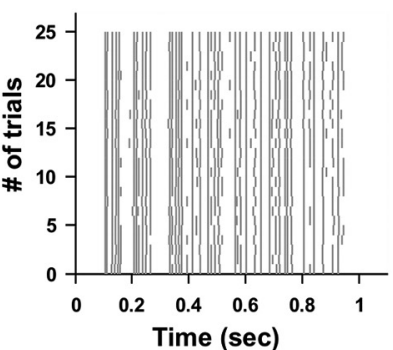

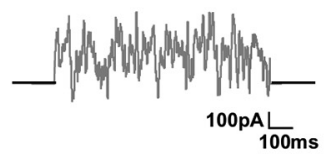

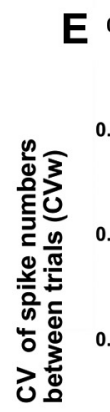

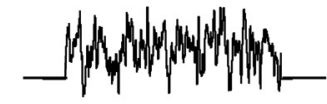

0.12

$\mathbf{F}$

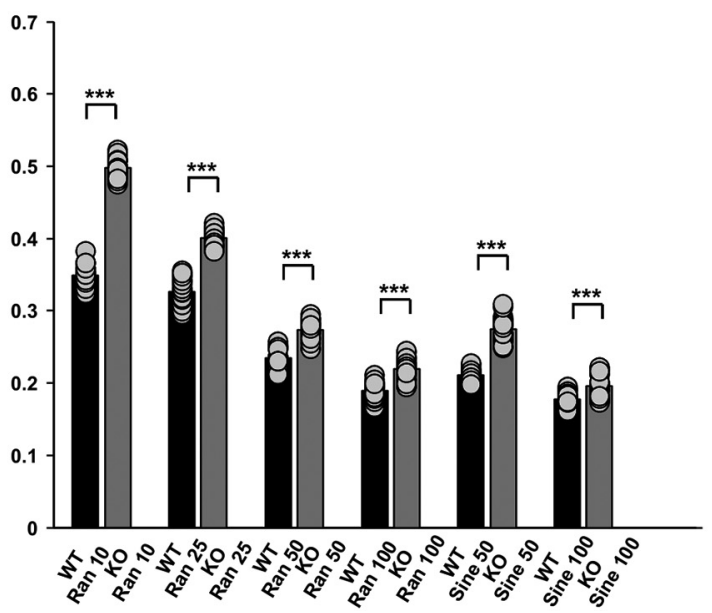

Figure 2. KO cells have increased $\mathrm{CV}_{b}$ for noise and sinusoidal stimuli but not $\mathrm{CV}_{w}$ across trials. $\boldsymbol{A}, \boldsymbol{B}$, Representative raw plot of spiking showing no spike variability or spike precision differ-

\section{Figure 2. continued}

ences for the Random 100 noise protocol across multiple trials for WT (black; $\boldsymbol{A}$ ) and for KO (gray; $\boldsymbol{B})$. The trace is for four superimposed trials. Calibration: $20 \mathrm{mV}, 200 \mathrm{~ms}$. C, $\boldsymbol{D}$, Raster plot showing no spike variability or spike precision differences for Random 100 noise protocol across multiple trials for WT (black; $\boldsymbol{C}$ ) and for KO (gray; $\boldsymbol{D}$ ). Trace below indicates Random 100 input protocol. Calibration: 100 pA, 100 ms. E, Bar plot for within-cell variability differences $\left(\mathrm{CV}_{w}\right)$ for all noise and sinusoidal protocols for WT (black bars) and KO (gray bars). The protocol is numbered by the SD in $\mathrm{pA}$ (random protocols) or sinewave amplitude (sine protocols; Random 10 protocol: $n=16$ for WT and $n=13$ for KO; Random 25 protocol: $n=16$ for WT and $n=13$ for $\mathrm{KO}$; Random 50 protocol: $n=10$ for both $\mathrm{WT}$ and $\mathrm{KO}$; Random 100 protocol: $n=10$ for both WT and KO; Sine 50 protocol: $n=10$ for both WT and KO; Sine 100 protocol: $n=10$ for both WT and KO; circles represent individual data points). No significant within-cell variability $\left(\mathrm{CV}_{w}\right)$ differences were seen between WT and KO cells in any protocol. $\boldsymbol{F}$, Bar plot for betweencell variability differences $\left(\mathrm{CV}_{b}\right)$ for all noise and sinusoidal protocols (Random 10 protocol: $n=16$ for WT and $n=13$ for $\mathrm{KO}$; Random 25 protocol: $n=16$ for WT and $n=13$ for $\mathrm{KO}$; Random 50 protocol: $n=10$ for both WT and KO; Random 100 protocol: $n=10$ for both WT and KO; Sine 50 protocol: $n=10$ for both WT and KO; Sine 100 protocol: $n=10$ for both WT and $\mathrm{KO})$. Significant differences were seen for all pairs $(p<0.001$; three-way ANOVA, circles represent individual data points'). $* * * p<0.001$.

for the analysis as this part showed peak SK current activity. The analysis was weakened because of our criterion that a cell should have minimum of two spikes for regression fit. Hence, several KO cells were rejected, although these were probably the ones that probably had the strongest effect of elevated SK channel activity (Fig. $1 K, L)$.

We observed increased within-cell variability (i.e., $\mathrm{CV}_{w}$ ), between-cell variability (i.e., $\mathrm{CV}_{b}$ ) of spike numbers and increased $\mathrm{CV}_{s 500}$ of spike timings, which are all indicative of abnormal coding in KO neurons. Thus, these initial recordings showed that there was increased heterogeneity in spiking in CA1 pyramidal neurons of KO mice.

\section{KO mice exhibit increased $\mathrm{CV}_{b}$ for frozen noise stimuli}

Neuronal coding takes place against a noisy background of continuous synaptic input (Faisal et al., 2008). Frozen noise stimuli have therefore been used in several studies to examine single-neuron computations and are considered more physiological (Stevens and Zador, 1998; Carandini, 2004; Fujisawa et al., 2004; Han and Boyden, 2007). We injected noise waveforms in the soma using a design similar to that of Mainen and Sejnowski (1995). The stimulus waveforms were mainly either of random noise or sinuosoidal input currents (for details, see Materials and Methods). The RMP was controlled by maintaining constant current injection into the cell while recording. All cells were held at a constant potential of $-65 \mathrm{mV}$ for all of the protocols. Cells were accepted only if the fluctuations in their potential while recordings were smaller than \pm 2.5 $\mathrm{mV}$. For noisy inputs, spikes across multiple trials aligned very precisely for both WT cells (Fig. $2 A, C$ ) and KO cells 
(Fig. 2B,D). On computation of $\mathrm{CV}$ of spike numbers across trials within a cell (i.e., $\mathrm{CV}_{w}$ ), there were no statistically significant differences for any of the protocols (Fig. $2 E)$. However, between-cell variability differences $\left(\mathrm{CV}_{b}\right)$ were still significantly elevated for KO cells, for all stimulus protocols (Fig. 2F). We performed a three-way ANOVA for all of the protocols on the number of spikes produced in respective protocols for WT and KO cells. The three factors were as follows: across trials, across cells, and WT versus KO cells. ANOVA results were significant across cells $(p<0.001)$ and for WT versus KO $(p<0.001)$, but not for across trials $(p=1)$ for all the protocols. Thus, between-cell variability $\left(\mathrm{CV}_{b}\right)$ reveals robust phenotypic differences, which are also observed between WT and KO cells for the input noise stimulus. The same is not true for across-trial within-cell $\left(\mathrm{CV}_{w}\right)$ differences.

\section{Spike imprecision diverges between KO and WT only in adult mice}

Fragile $X$ is known to have an age-dependent effect where some disease phenotypes get worse with age (Larson, 2005; Cornish et al., 2008; Choi et al., 2010). We asked whether similar effects of age might manifest in the phenotype of the firing imprecision of KO cells. We therefore repeated our experimental protocols in young (3- to 4-week-old) male WT and KO littermate mice. Regular spike firing was observed in both KO and WT cells for step input current injection (Fig. $3 A-C$ ). As before, we assessed the variability of spike numbers across multiple trials within the cell $\left(\mathrm{CV}_{w}\right)$. There was no significant difference between WT and KO cells in these younger mice $\left(\mathrm{CV}_{w}\right.$ for WT, $0.041 \pm 0.006, n=26$ cells; $\mathrm{CV}_{w}$ for $\mathrm{KO}$, $0.03 \pm 0.002, n=19$ cells; $p=0.81$, Wilcoxon rank sum test; Fig. $3 A-D$ ). Spike precision was assessed as above by finding the $\mathrm{CV}_{s 500}$. By this measure too, no significant difference in the precision of spike timings was found for $\mathrm{KO}$ compared with WT $\left(\mathrm{CV}_{\text {s500 }}\right.$ wT younger, $0.133 \pm 0.02, n$ $=26$ cells; $\mathrm{CV}_{\text {s500_KO younger }} 0.103 \pm 0.01, n=19$ cells; $p$ $=0.82$, Wilcoxon rank sum test; Fig. $3 E$ ). We used a two-way ANOVA interaction model for assessing agedependent differences in spiking variability across different trials in a cell $\left(\mathrm{CV}_{w} ; F_{(1,100)}=4.97, p=0.028\right.$ for WT and $\mathrm{KO}$ differences; $F_{(1,100)}=8.05, p=0.005$ for interaction factor; two-way ANOVA with interaction model, $t$ test with Bonferroni corrections post hoc; Fig. 3D). We also estimated differences in spike timing precision across different trials in a cell $\left(\mathrm{CV}_{s 500} ; F_{(1,99)}=7.47, p=0.007\right.$ for age factor; $F_{(1,99)}=9.46, p=0.003$ for interaction factor; two-way ANOVA with interaction model, $t$ test with Bonferroni corrections; Fig. $3 E$ ). Spike timing precision differences were also assessed by jitter slope analysis $\left(F_{(1,92)}=\right.$ 6.83, $p=0.011$ for interaction factor; $F_{(1,92)}=2.2, p=$ 0.14 for age factor; two-way ANOVA with interaction model, $t$ test with Bonferroni corrections; Fig. 3F). ANOVA indicated a significant interaction between the two factors age and genotype of the animal. Using post hoc tests, we concluded that for $\mathrm{KO}$ cells there is a worsening of phenotype for both variability in spiking number $\left(\mathrm{CV}_{w}\right)$ across multiple trials within a cell and in spike timing precision $\left(\mathrm{CV}_{s 500}\right.$ of ISI) across multiple trials within a cell (Fig. $3 D-F$;
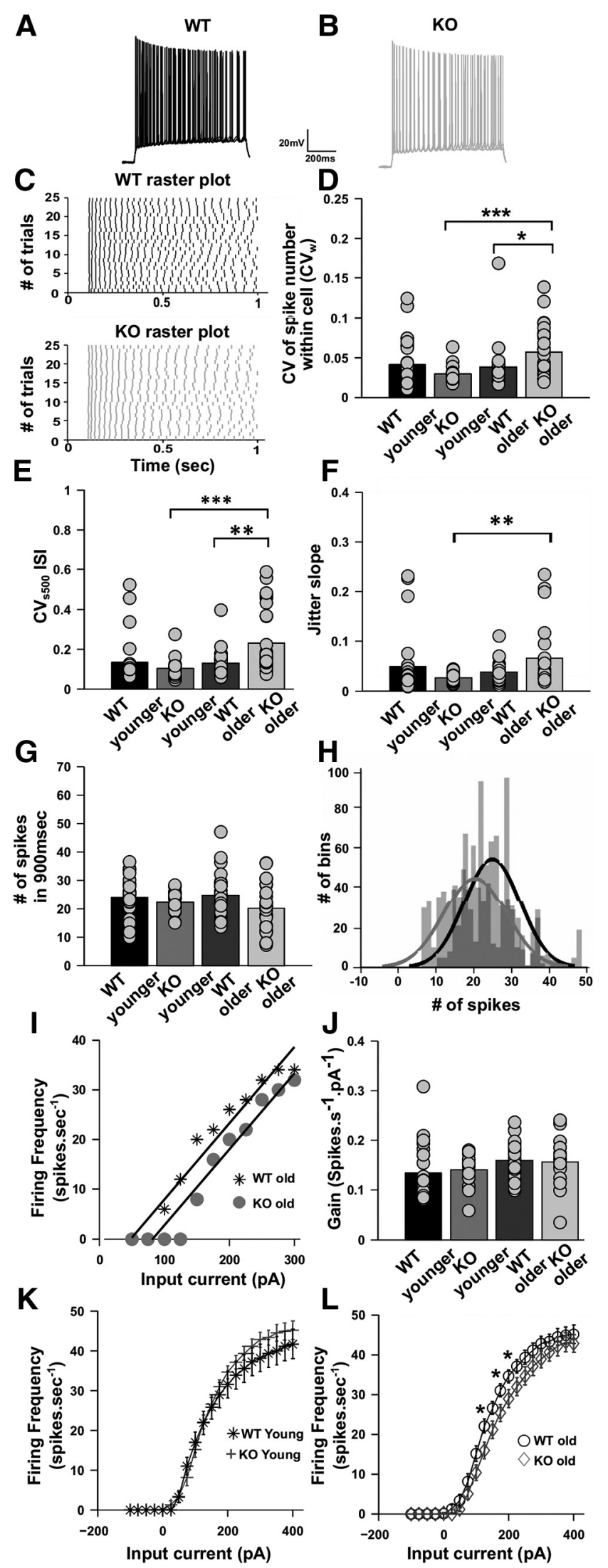

Figure 3. Spiking variability and spike imprecision diverges in adult $\mathrm{KO}$ animals compared with younger KO animals, but not in WT animals. $\boldsymbol{A}, \boldsymbol{B}$, Representative raw traces of spiking, superimposed 


\section{continued}

for four trials only for WT younger (black) and KO younger (gray). Calibration: 20 mV, 200 ms. C, Representative raster plots showing spiking for the step depolarization protocol for WT younger (black) and $\mathrm{KO}$ younger (gray) animals. Spikes align precisely and have low within-cell variability $\left(\mathrm{CV}_{w}\right)$ across trials for $\mathrm{KO}$ younger compared with WT younger animals. $\boldsymbol{D}$, Bar plot for comparing within-cell variability $\left(\mathrm{CV}_{w}\right)$ across multiple trials among WT younger $(n=26$ cells, black), KO younger ( $n=19$ cells, gray), WT older ( $n=30$ cells, light black), and KO older ( $n=29$ cells, light gray) animals. Spiking variability significantly increases for $\mathrm{KO}$ animals with age but not for WT animals $(p=0.005$ for interaction factor between age and genotype; two-way ANOVA). E, Bar plot for $\mathrm{CV}_{s 500}$ for the ISI of the step input protocol, a measure of spike precision for all groups. Spiking precision significantly decreases for $\mathrm{KO}$ animals with age but not for WT animals $(p=0.003$ for interaction factor between age and genotype; two-way ANOVA). $\boldsymbol{F}$, Bar plot for jitter slope analysis, a measure of spike precision for all groups, as mentioned in $\boldsymbol{E}$. Spiking precision significantly decreases for $\mathrm{KO}$ animals with age but not for WT animals. The only significant differences emerge between $\mathrm{KO}$ young and $\mathrm{KO}$ old animals $\left(F_{(1,92)}=6.83 ; p=0.011\right.$ for interaction factor between age and genotype; two-way ANOVA; error bars represent the SEM). $\mathbf{G}$, Comparison of the number of spikes produced during the $900 \mathrm{~ms}$ stimulus period for each of the groups in $\boldsymbol{E}$. There is a nonsignificant change in spike number with age in WT or KO animals ( $p=0.6$; two-way ANOVA), but there was a significant reduction in spike number for $\mathrm{KO}$ animals compared with WT animals ( $p=0.021$; two-way ANOVA). $\boldsymbol{H}$, Superimposed histograms for the number of spikes produced for WT older (light gray) and for KO older (dark gray) animals. Solid lines represent Gaussian fitting. The shift in peaks of the histograms shows that there is a greater spread in spike numbers produced in given trials for KO compared with WT animals ( $p<0.001$; three-way ANOVA). I, Illustrative $\mathrm{f}-\mathrm{I}$ curves for a representative cell from older $(>6$ weeks of age) WT animals (black stars) and a cell from older KO animals (filled gray circles). The gain (i.e., slope) for each cell was computed using a regression fit in the approximately linear domain between 50 and 300 pA. $\boldsymbol{J}$, Gain computed by fitting a regression line through the $\mathrm{f}-\mathrm{I}$ curve for each cell as illustrated in $\boldsymbol{I}$, for each of the four experimental conditions. The cells were the same as in $\mathbf{G}$. The gains are not significantly different between WT and KO animals in any age group ( $n=27$ cells for WT older and $n=25$ cells for KO older animals; $n=26$ cells for WT younger and $n=19$ cells for $\mathrm{KO}$ younger animals; $F_{(1,94)}=0.03 ; p=0.86$ for $\mathrm{WT}$ and $\mathrm{KO}$ differences; two-way ANOVA). $\boldsymbol{K}, \mathrm{f}-\mathrm{I}$ curve for younger WT (black stars, $n=26$ cells) versus younger KO (gray plus, 19 cells) CA1 cells. There is no significant difference between WT and KO cells at this age $\left(F_{(1,923)}=0.92 ; p=0.33\right.$ for $\mathrm{WT}$ and $\mathrm{KO}$ differences; two-way ANOVA, error bar represents the SEM). $L, f-I$ curve for older WT (black circles, $n=27$ cells) versus older KO (gray diamonds, 25 cells) CA1 cells. There is a significant difference between WT and $\mathrm{KO}$ cells at this age $\left(F_{(1,1070)}=31.03 ; p<0.001\right.$ for $\mathrm{WT}$ and $\mathrm{KO}$ differences; two-way ANOVA, error bar represents the SEM). ***p $<0.001, * * p<0.01, * p<0.05$.

Table 1, detailed statistics). However, the same was not seen in WT cells. A two-way ANOVA was performed on the number of spikes produced in the $900 \mathrm{~ms}$ stimulus period used in the step depolarization protocol (Fig. 1A). In this ANOVA, the two factors were young versus old animals and WT versus KO. There was no significant change between the ages of the animals for both WT and $\mathrm{KO}\left(F_{(1,10)}=0.31 ; p=0.6\right.$; two-way ANOVA, $t$ test with Bonferroni correction), but there was a significant reduc- tion in spike number for $\mathrm{KO}$ animals compared with WT animals $\left(F_{(1,101)}=4.7 ; p=0.032\right.$; two-way ANOVA, $t$ test with Bonferroni correction; Fig. 3G). However, the $f-I$ curves were not significantly different between WT and $\mathrm{KO}$ animals in either in the older (8 weeks) or younger (4 weeks) age groups, when the slope of the $f-I$ curves (gain) was used as a readout (mean gain for $f-I$ curve for older WT animals, $0.16 \pm 0.007$ spikes $\cdot \mathrm{s}^{-1} \cdot \mathrm{pA}^{-1}, n=27$ cells; mean gain for $\mathrm{f}-\mathrm{I}$ curve for older $\mathrm{KO}$ animals, $0.16 \pm$ 0.008 spikes $\cdot \mathrm{s}^{-1} \cdot \mathrm{pA}^{-1}, n=25$ cells; mean gain for $\mathrm{f}-\mathrm{I}$ curve for younger WT animals, $0.133 \pm 0.01$ spikes $\cdot \mathrm{s}^{-1}$ - $\mathrm{pA}^{-1}, n=26$ cells; mean gain for $\mathrm{f}-\mathrm{I}$ curve younger $\mathrm{KO}$ animals, $0.136 \pm 0.013$ spikes $\cdot \mathrm{s}^{-1} \cdot \mathrm{pA}^{-1}, n=19$ cells; $F_{(1,94)}=0.03, p=0.86$ for $\mathrm{WT}$ and $\mathrm{KO}$ differences; two-way ANOVA, $t$ test with Bonferroni correction; Fig. $3 /, J)$. When comparisons were made of $f-I$ curves of WT and KOs cells, there was reduced excitability seen for some input currents in older animals (mean number of spikes for an input current of $125 \mathrm{pA}$ in WT animals, 22.07 $\pm 1.74 ; n=27$ cells; mean number of spikes for input current of $125 \mathrm{pA}$ in $\mathrm{KO}$ animals, $15.92 \pm 2.1 ; n=25$ cells; $F_{(1,1070)}=31.03, p<0.001$; two-way ANOVA; Fig. $\left.3 L\right)$, but not in younger animals (mean number of spikes for input current of $125 \mathrm{pA}$ in WT animals, $21.8 \pm 2.9 ; n=26$ cells; mean number of spikes for input current of $125 \mathrm{pA}$ in KO animals, $22.8 \pm 2.9 ; n=19$ cells, $F_{(1,923)}=0.92, p=0.33$; two-way ANOVA, $t$ test with Bonferroni correction as post hoc; Fig. $3 K)$. Other properties like spike threshold were not significantly different between WT and KO cells (spike threshold for the first spike in WT, $-53.6 \pm 0.56 \mathrm{mV}, n=$ 30 cells; spike threshold for first spike KO, $-53.8 \pm 0.62$ $\mathrm{mV}, n=29$ cells; spike threshold for the last spike WT, $-41.9 \pm 0.66 \mathrm{mV}, n=30$ cells; spike threshold for the last spike $\mathrm{KO},-43.5 \pm 0.66 \mathrm{mV}, n=29$ cells; $F_{(1,115)}=1.98$, $p=0.16$, two-way ANOVA, $t$ test with Bonferroni correction as post hoc test. The spread in the number of spikes produced by KO neurons was greater than observed in WT neurons, further substantiating the point of increased variability in $\mathrm{KO}$ neurons (SD of spike numbers for WT $=$ $7.2 ; n=750$ spikes from 30 cells 25 trials each; SD of spike numbers for $\mathrm{KO}=8.1 ; n=725$ spikes from 29 cells 25 trials each; Fig. $3 H$ ). We performed a three-way ANOVA in which the factors were as follows: across trials, across cells, and WT versus KO for older age group data. The ANOVA results were highly significant for the variability in spike numbers between cells $\left(\mathrm{CV}_{b} ; F_{(29,1420)}=32.04\right.$, $p<0.001$ ) and differences in spike numbers between WT and KO for older animals $\left(F_{(1,1420)}=209.9, p<0.001\right)$, but across-trial comparisons did not exhibit a significant difference $\left(F_{(24,1420)}=0.15, p=1\right)$. Thus, there is an increase in spike variability with lowered spiking precision for adult $\mathrm{KO}$ mice compared with juvenile KO mice. This divergence that is observed for $\mathrm{KO}$ animals with age does not happen for WT animals.

\section{Differential effect of FMRP KO in different brain regions}

Mouse models of FXS are known to exhibit increased excitability (Contractor et al., 2015; Deng and Klyachko, 2016; Luque et al., 2017). In contrast to previous studies, 
Table 1: Detailed statistics used in different figures

\begin{tabular}{|c|c|c|c|}
\hline $\begin{array}{l}\text { Figure } \\
\text { number }\end{array}$ & $\begin{array}{c}\text { Data } \\
\text { structure }\end{array}$ & Type of test & Statistics \\
\hline Figure $1 E$ & Non-normal & Wilcoxon rank sum test & $p=0.0048$ for $\mathrm{CV}_{w}$ differences between WT older and $\mathrm{KO}$ older \\
\hline Figure $1 F$ & Non-normal & Wilcoxon rank sum test & $p<0.001$ for $\mathrm{CV}_{b}$ differences between WT older and KO older \\
\hline Figure $1 \mathrm{~J}$ & Non-normal & Two-way ANOVA & $F_{(1,113)}=5.78 ; p=0.018$ for WT vs KO differences \\
\hline Figure $1 L$ & Non-normal & Wilcoxon rank sum test & $p=0.14$ for jitter slope differences between WT older and KO older \\
\hline Figure $2 E$ & Normal & Three-way ANOVA & $p<0.001$ for $\mathrm{CV}_{w}$ differences between WT older and KO older \\
\hline Figure $2 F$ & Normal & Three-way ANOVA & $p<0.001$ for $\mathrm{CV}_{b}$ differences between WT older and $\mathrm{KO}$ older \\
\hline Figure $3 D$ & Normal & Two-way ANOVA & $\begin{array}{l}F_{(1,100)}=4.97 ; p=0.028 \text { for WT and KO differences; } F_{(1,100)}=8.05 ; p=0.005 \text { for interaction } \\
\text { factor between age and genotype; } p=0.7 \text {, for WT older vs WT younger; } p<0.001 \text { for KO } \\
\text { older vs KO younger, } t \text { test with Bonferroni correction }\end{array}$ \\
\hline Figure $3 E$ & Normal & Two-way ANOVA & $\begin{array}{l}F_{(1,99)}=7.47, p=0.007 \text { for age factor; } F_{(1,99)}=9.46 ; p=0.003 \text { for interaction factor } \\
\text { between age and genotype; } p=0.0002 \text { for KO older vs KO younger; } p=0.9 \text { for WT older vs } \\
\text { WT younger; } p=0.0025 \text { for WT older and KO older }\end{array}$ \\
\hline Figure $3 F$ & Normal & Two-way ANOVA & $\begin{array}{l}F_{(1,92)}=6.83, p=0.011 \text { for interaction factor between age and genotype, } F_{(1,92)}=2.2, p= \\
0.14 \text { for age factor; } p=0.052 \text { for WT older and KO older; } p=0.007 \text { for KO older and KO } \\
\text { younger; } p=0.4 \text { for WT older and WT younger }\end{array}$ \\
\hline Figure $3 G$ & Normal & Two-way ANOVA & $\begin{array}{l}F_{(1,100)}=4.71 ; p=0.032 \text { for spike number between } \mathrm{WT} \text { and } \mathrm{KO} ; p=0.029 \text { between WT old } \\
\text { and KO old; } p=0.3 \text { between WT young and KO young }\end{array}$ \\
\hline Figure $3 J$ & Normal & Two-way ANOVA & $F_{(1,94)}=0.03 ; p=0.86$ for WT and $\mathrm{KO}$ differences \\
\hline Figure $3 K$ & Normal & Two-way ANOVA & $F_{(1,923)}=0.92 ; p=0.33 ; \mathrm{WT}$ and $\mathrm{KO}$ differences at young age group \\
\hline Figure $3 L$ & Normal & Two-way ANOVA & $F_{(1,1070)}=31.03 p<0.001 ; \mathrm{WT}$ and KO differences at old age group \\
\hline Figure $4 B$ & Normal & Two-way ANOVA & $F_{(1,72)}=5.35 ; p=0.023$ for difference between WT and KO CA3 cells younger animals \\
\hline Figure $4 D$ & Normal & Two-way ANOVA & $F_{(1,88)}=1.06 ; p=0.31$ for difference between WT and KO CA1 cells younger animals \\
\hline Figure $4 F$ & Normal & Two-way ANOVA & $F_{(1,75)}=1.16 ; p=0.28$ for difference between WT and KO CA3 cells older animals \\
\hline Figure $4 H$ & Normal & Two-way ANOVA & $F_{(1,59)}=7.42 ; p=0.009$ for difference between WT and KO CA1 cells for older animals \\
\hline Figure $5 \mathrm{C}$ & Normal & Two-way ANOVA & $\begin{array}{l}F_{(1,46)}=4.8 ; p=0.033 \text { for mAHP WT and KO differences. } p=0.2 \text { between WT younger and } \\
\text { KO younger; } p=0.018 \text { for WT older and KO older }\end{array}$ \\
\hline Figure $5 D$ & Normal & Two-way ANOVA & $\begin{array}{l}F_{(1,54)}=8.84 ; p=0.004 \text { for sAHP WT and KO differences; } p=0.07 \text { between WT younger } \\
\text { and KO younger; } p=0.008 \text { for WT older and KO older }\end{array}$ \\
\hline Figure $5 F$ & Non-normal & Wilcoxon rank sum test & $p=0.91$ for $I_{\mathrm{h}}$ percentage of sag between $\mathrm{WT}$ and $\mathrm{KO}$ \\
\hline Figure $5 \mathrm{H}$ & Normal & Two-way ANOVA & $F_{(1,258)}=2.54 ; p=0.11$ between $\mathrm{WT}$ and $\mathrm{KO}$ for $\mathrm{I}_{\mathrm{M}}$ current \\
\hline Figure $6 C$ & Normal & Two-way ANOVA & $F_{(1,240)}=33.3 ; p<0.001$ for WT older and KO older SK currents \\
\hline Figure $6 D$ & Normal & Two-way ANOVA & $F_{(1,189)}=0.51 ; p=0.5$ for WT younger and $\mathrm{KO}$ younger SK currents \\
\hline Figure $6 E$ & Normal & Two-way ANOVA & $F_{(1,229)}=0.01 ; p=0.9$ for WT older and WT younger SK currents \\
\hline Figure $6 F$ & Normal & Two-way ANOVA & $F_{(1,209)}=21.02 ; p<0.001$ for $\mathrm{KO}$ older and $\mathrm{KO}$ younger SK currents \\
\hline Figure $7 B$ & Normal & Two-way ANOVA & $F_{(1,24)}=0.48 ; p=0.5$ for $\mathrm{WT}$ younger vs $\mathrm{KO}$ younger for $\mathrm{CA} 3$ \\
\hline Figure $7 C$ & Normal & Two-way ANOVA & $F_{(1,24)}=0.21 ; p=0.6$ for WT younger vs $\mathrm{KO}$ younger for CA1 \\
\hline Figure $7 D$ & Normal & Two-way ANOVA & $F_{(1,24)}=0.3 ; p=0.6$ for WT older vs KO older for CA3 \\
\hline Figure $7 E$ & Normal & Two-way ANOVA & $F_{(1,24)}=0.25 ; p=0.61$ for WT older vs $\mathrm{KO}$ older for CA1 \\
\hline Figure $8 E$ & Normal & Two-way ANOVA & $F_{(1,48)}=0 ; p=0.96$ for effect of apamin; $F_{(1,49)}=8.74 ; p=0.005$ for WT and KO differences \\
\hline Figure $8 F$ & Normal & Two-way ANOVA & $\begin{array}{l}F_{(1,96)}=157.5 ; p<0.001 \text { for WT and KO differences; } F_{(1,96)}=53.1 ; p<0.001 \text { for effect of } \\
\text { apamin on } \mathrm{CV}_{b}\end{array}$ \\
\hline Figure $8 G$ & Normal & Two-way ANOVA & $\begin{array}{l}F_{(1,49)}=9.63 ; p=0.003 \text { for WT and KO differences; } F_{(1,49)}=2.87 ; p=0.09 \text { for effect of } \\
\text { apamin; } p=0.006 \text { for WT pre apamin and KO pre apamin; } p=0.05 \text { for KO pre apamin and } \\
\text { KO post apamin; } p=0.23 \text { WT pre apamin and KO post apamin }\end{array}$ \\
\hline Figure $8 \mathrm{H}$ & Normal & Two-way ANOVA & $F_{(1,41)}=2.1 ; p=0.15$ for effect of apamin; $F_{(1,41)}=3.6 ; p=0.06$ for WT and KO differences \\
\hline Figure 81 & Normal & Two-way ANOVA & $\begin{array}{l}F_{(1,81)}=2.7 ; p=0.1 \text { for differences between WT and KO; } F_{(1,81)}=40.5 p<0.001 \text { for effect } \\
\text { of BAPTA }\end{array}$ \\
\hline
\end{tabular}

It is to be noted that all of the data in figures is from CA1 cells except in Figure 4, where it is from both CA3 and CA1 cells

we observed that excitability was reduced in CA1 neurons in adult mice, but not in juveniles. Deng et al. (2019) have observed increased CA3 excitability in juveniles, which was in contrast to what we observed in CA1, namely, that there is no significant effect on excitability of CA1 pyramidal cells at this time point. To address this contrasting result, we repeated the protocol from Deng et al. (2019) in our FXS model and compared outcomes between CA3 and CA1 (Fig. 4). In agreement with their study, we observed significantly increased spiking in CA3 cells of FXS mice for some of the input holding currents (number of spikes in $60 \mathrm{~s}$ for $-48 \mathrm{mV}$ holding potential for WT, 131.9 $\pm 17.42, n=10$ cells; number of spikes in $60 \mathrm{~s}$ for -48 $\mathrm{mV}$ holding potential for $\mathrm{KO}, 186.3 \pm 27.27, n=10$ cells; $F_{(1,72)}=5.35, p=0.023$ for difference between WT and KO; two-way ANOVA, Sidak's post hoc test; Fig. $4 A, B$ ). We performed similar experiments in CA1 pyramidal cells, using the same protocol as in Figure 4, $A$ and $B$. We did not find any difference in excitability between WT and KO (number of spikes in $60 \mathrm{~s}$ for $-48 \mathrm{mV}$ holding potential for WT, $355.58 \pm 40.93, n=12$ cells; number of spikes in 60 $\mathrm{s}$ for $-48 \mathrm{mV}$ holding potential for $\mathrm{KO}, 358.67 \pm 22.56, n$ $=12$ cells; $F_{(1,88)}=1.06, p=0.31$ for difference between WT and KO; two-way ANOVA, Sidak's post hoc test; Fig. $4 C, D)$. On seeing this differential effect of FMRP $K O$ in different regions of hippocampus, we were interested to see whether this might be a function of age. Therefore, we recorded similar protocols from CA3 and CA1 of older animals. We found that the hyperexcitability seen in younger CA3 cells goes away, leading to no significant difference in the spiking activity in these cells for WT versus KO (number of spikes in $60 \mathrm{~s}$ for $-48 \mathrm{mV}$ holding potential for WT, $313.6 \pm 83.8, n=10$ cells; number of spikes in $60 \mathrm{~s}$ for $-48 \mathrm{mV}$ holding potential for $\mathrm{KO}, 181.1$ 
A
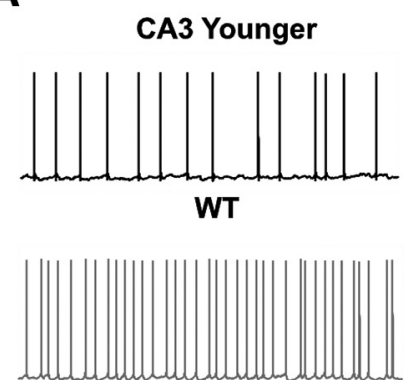

KO

C

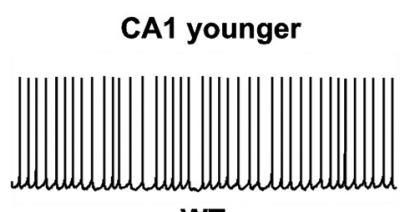

WT

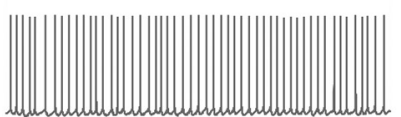

KO

E

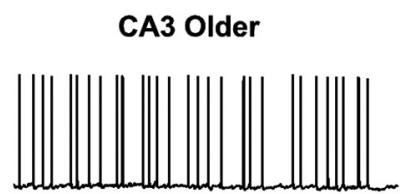

WT

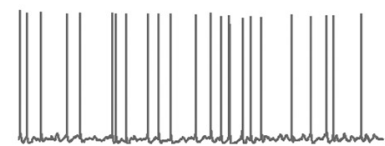

KO

G

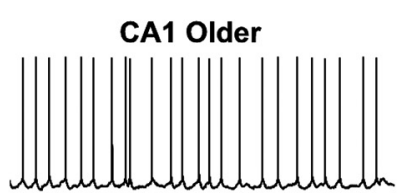

WT

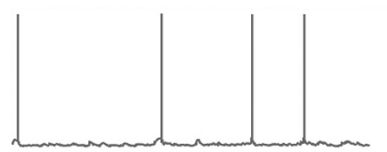

KO

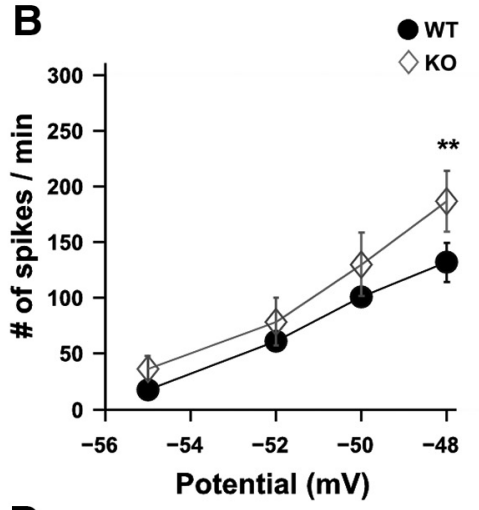

D

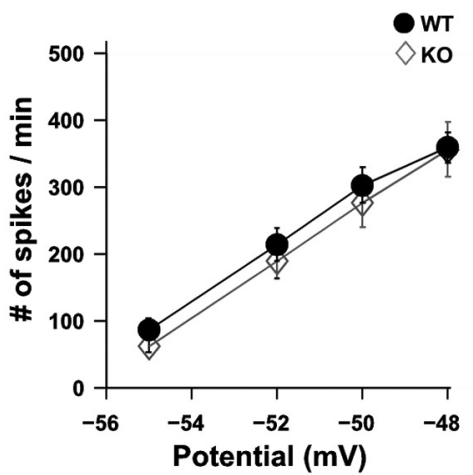

F

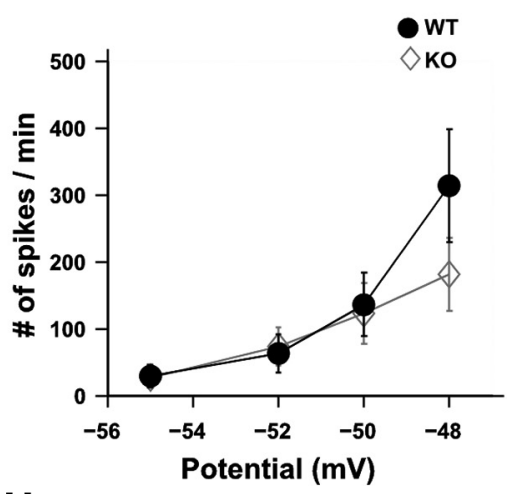

H

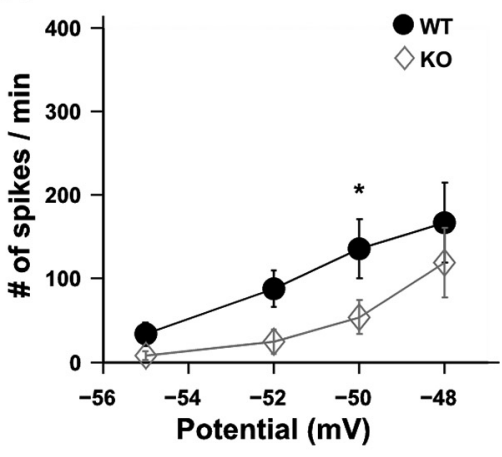

$20 \mathrm{mVL}$

Figure 4. Contrasting effects of FMRP KO in different regions of hippocampus. $\boldsymbol{A}$, Representative traces showing increased excitability between WT (black) and KO (gray) CA3 cells in younger animals. Traces are from the recording where the cells are held at $-48 \mathrm{mV}$. Calibration: $20 \mathrm{mV}, 1 \mathrm{~s}$. B. Line plot showing increased excitability for KO CA3 cells $(n=10$ cells, gray diamond) compared with WT CA3 cells ( $n=10$ cells, filled black circles), when the cells were held at $-48 \mathrm{mV}$, for younger animals. For other holding 
continued

potentials, the spike numbers are not significantly increased for KO cells $\left(F_{(1,72)}=5.35, p=0.023\right.$ for difference between WT and KO; two-way ANOVA, error bar represents the SEM). C, Representative traces showing no change in excitability between WT (black) and $\mathrm{KO}$ (gray) CA1 cells in younger animals. Traces are from the recording where the cells are held at $-48 \mathrm{mV}$. Calibration: $20 \mathrm{mV}, 1 \mathrm{~s}$. $\boldsymbol{D}$, Line plot showing no change in excitability for KO CA1 cells $(n=12$ cells, gray diamond) compared with WT CA1 cells in younger animals $\left(n=12\right.$ cells, filled black circles; $F_{(1,88)}=1.06, p=0.31$ for difference between WT and KO; two-way ANOVA, error bar represents the SEM). $\boldsymbol{E}$, Representative traces showing no change in excitability between WT (black) and KO (gray) CA3 cells in older animals. Traces are from the recording where the cells are held at $-48 \mathrm{mV}$. Calibration: $20 \mathrm{mV}, 1 \mathrm{~s}$. F, Line plot showing no change in excitability for KO CA3 cells ( $n=10$ cells, gray diamond) compared with WT CA3 cells in older animals $(n=10$ cells, filled black circles; $F_{(1,72)}=1.17, p=0.28$ for difference between WT and KO; two-way ANOVA, error bar represents the SEM). G, Representative traces showing reduced excitability for $\mathrm{KO}$ cells (gray) compared with (black) and KO CA1 cells in older animals. Traces are from the recording where the cells are held at $-50 \mathrm{mV}$. Calibration: $20 \mathrm{mV}, 1 \mathrm{~s}$. $\boldsymbol{H}$, Line plot showing decreased excitability for KO CA1 cells ( $n=8$ cells, gray diamond) compared with WT CA1 cells $(n=8$ cells, filled black circles), when the cells were held at $-50 \mathrm{mV}$, for older animals. For other holding potentials, the spike numbers are not significantly decreased for $\mathrm{KO}$ cells $\left(F_{(1,59)}=7.42, p=0.009\right.$ for difference between WT and KO; two-way ANOVA, error bar represents the SEM). $* * p<0.01, * p<0.05$.

$\pm 54.9, n=10$ cells; $F_{(1,75)}=1.16, p=0.28$ for difference between WT and KO; two-way ANOVA, Sidak's post hoc test; Fig. 4E,F). In agreement with our previous results, as shown in Figure 3, we observed reduced excitability in CA1 KO cells compared with WT cells (number of spikes in $60 \mathrm{~s}$ for $-50 \mathrm{mV}$ holding potential for WT, $135.6 \pm 35.2$, $n=8$ cells; number of spikes in $60 \mathrm{~s}$ for $-50 \mathrm{mV}$ holding potential for KO, $54 \pm 20.4, n=8$ cells; $F_{(1,59)}=7.42, p=$ 0.009 for difference between WT and KO; two-way ANOVA, Sidak's post hoc test; Fig. 4G,H). Using these experiments, we were able to replicate previous published results of Deng et al. (2019). In addition, we found that there were contrasting and age-dependent effects of FMRP KO on the spiking properties of CA1 and CA3 pyramidal neurons.

\section{mAHP currents are elevated in older $\mathrm{KO}$ animals compared with WT but no significant changes in $I_{\mathrm{h}}$ and $M$ currents}

We next investigated the mechanisms for increased variability in $\mathrm{KO}$ animals, on the basis of the above observations of increased variability and fewer spikes (Fig. $3 D, G, L)$ in the later part of the current pulse. In particular, we hypothesized that mAHP and SAHP currents were likely candidates to mediate such slower-onset effects. We asked whether these currents might be altered in FXS cells.

To test this hypothesis, we compared AHPs for WT versus $\mathrm{KO}$ in older and younger animals. Cells were held at $-70 \mathrm{mV}$ to record AHPs. We quantified AHPs by examining the hyperpolarization elicited with a spike train of five spikes in $100 \mathrm{~ms}$. Hyperpolarization was quantified at mAHP peak (50 ms after the spike train) and at sAHP peak (200 ms after the spike train). We found that mAHP was elevated only in older KOs but not in younger KOs when compared with their WT littermates (mAHP for older WTs, $-0.18 \pm 0.14, n=12$ cells; mAHP for older KOs, $-0.71 \pm 0.14 ; n=13$ cells; mAHP for younger WTs, -0.6 $\pm 0.19, n=14$ cells; mAHP for younger KOs, $-1.04 \pm$ $0.4, n=18$ cells; $F_{(1,46)}=4.8, p=0.033$ for WT and $\mathrm{KO}$ differences; two-way ANOVA, $t$ test with Bonferroni correction; Fig. 5C, Table 1, detailed statistics). We found similar results for SAHP measurements as well. We found that SAHP was significantly elevated only for older KO animals compared with their WT littermates but not sig- nificantly different for younger $\mathrm{KO}$ animals compared with their younger WT littermates (sAHP for older WTs, $0.05 \pm$ $0.09, n=12$ cells; sAHP for older KOs, $0.4 \pm 0.11 ; n=13$ cells; sAHP for younger WTs, $0.07 \pm 0.12, n=14$ cells; sAHP for younger KOs, $0.5 \pm 0.17, n=18$ cells; $F_{(1,54)}=$ 8.84, $p=0.004$ for WT and KO differences; two-way ANOVA, $t$ test with Bonferroni correction; Fig. 5D). As there was no significant difference in spike variability and spike time precision in younger $\mathrm{KO}$ animals, we hypothesized that the observed spiking variability in older KO animals might be due to elevated mAHPs, which has a strong change with age in $\mathrm{KO}$ animals. Further, the stimulus period used in the previous experiments (Fig. 1) was of $900 \mathrm{~ms}$, which is the peak time of activation for mAHP mediating ion channels.

The mAHP in CA1 cells is mediated by $I_{\mathrm{h}}, \mathrm{M}$, and SK currents. A previous study has shown that $I_{\mathrm{h}}$ voltage sag is not significantly altered in soma of FXS cells (Brager et al., 2012). M currents are known to affect the RMP and spike adaptation index (Madison et al., 1987; Guan et al., 2011; Nigro et al., 2014; Hönigsperger et al., 2015). Neither RMP nor spike adaptation index were significantly changed in FXS cells, indicating that M currents might not be responsible for the observed phenotype. To further test this idea, $I_{\mathrm{h}}$ voltage sag and $\mathrm{M}$ currents were recorded from soma of CA1 cells and compared between WT and KO cells for adult animals. As there was no difference in $\mathrm{MAHP}$ at juvenile stage for $\mathrm{KO}$ cells, we did not measure their $I_{\mathrm{h}}$ voltage sag and $\mathrm{M}$ currents. $I_{\mathrm{h}}$ channel activity was recorded using a hyperpolarization pulse. The voltage sag produced in response to the pulse, was quantified according to a method adapted from Brager et al. (2012; see Materials and Methods; Fig. 5E). As observed previously, there was no significant difference in $I_{\mathrm{h}}$ sag between WT and KO CA1 cells, at somatic level (percentage of sag for WT, $17.7 \pm 1.64, n=10$ cells; percentage of sag for KO, $18.87 \pm 2.51, n=10$ cells; $p=$ 0.91, Wilcoxon rank sum test; Fig. 5F).

To measure $M$ currents, we used the protocol adapted from Shah et al., 2002 (Materials and Methods). According to the protocol, the cells were held at $-20 \mathrm{mV}$ and $\mathrm{M}$ currents were deactivated in steps from -20 to $-80 \mathrm{mV}$. M current-specific blocker XE991 was used to obtain the postblocker trace. Postblocker trace was subtracted from preblocker trace to obtain XE991-sensitive M currents 
A

B

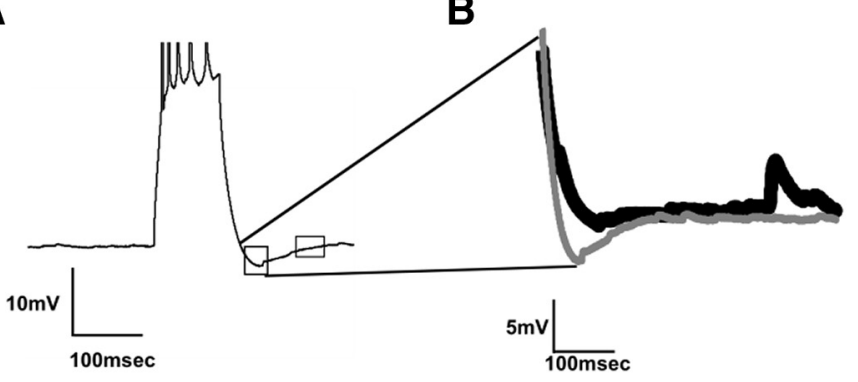

C

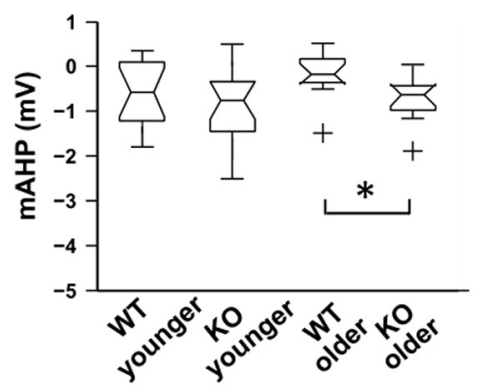

E
D

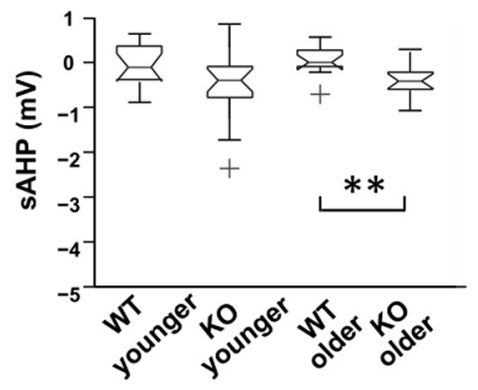

$F$

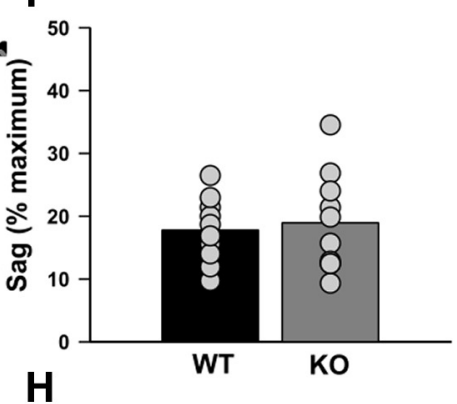

H

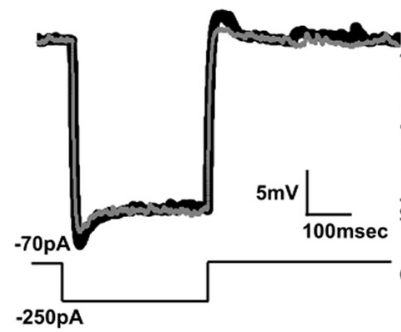

G
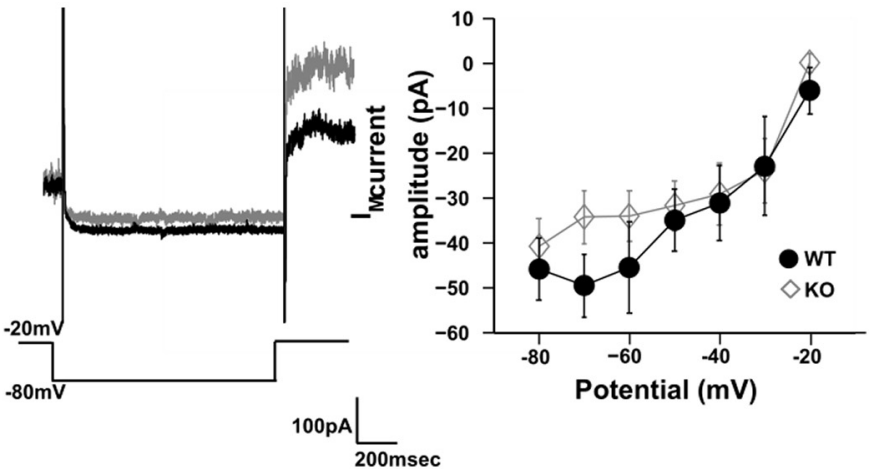

Figure 5. mAHP and sAHP are elevated in FXS KO neurons. A, Representative trace for the protocol to measure mAHP and sAHP. Hyperpolarization within $50 \mathrm{~ms}$ of the spike train (1) is quantified as mAHP, while hyperpolarization following the spike train 200 ms after the spike train (2) is quantified as SAHP. Calibration: $10 \mathrm{mV}, 100 \mathrm{~ms}$. B, Superimposed traces of WT older and KO older AHP currents showing elevated mAHP currents for KO cell (gray) compared with WT cell (black). Calibration: $5 \mathrm{mV}, 100 \mathrm{~ms}$. $\boldsymbol{C}$, Box plot showing mAHP currents for all groups $(n=12$ cells for WT older animals, $n=13$ cells for KO older animals, $n=14$ cells for WT younger animals, and $n=18$ cells for KO younger animals). mAHP values are elevated only for older KO animals versus older WT animals $(p=0.033$, two-way ANOVA, plus sign denotes an outlier). $\boldsymbol{D}$, Box plot showing sAHP currents for all groups ( $n=12$ cells for WT older animals, $n=13$ cells for KO older animals, $n=14$ cells for WT younger animals, and $n=18$ cells for KO younger animals). sAHP values are elevated only for older KO animals versus older WT animals $(p=0.004$, two-way ANOVA, plus sign denotes an outlier). $\boldsymbol{E}$, Representative trace for the protocol to measure $I_{\mathrm{h}}$ voltage deflection. Superimposed traces of WT (black) and KO (gray) showing no significant difference in the response. Sag produced in response to $250 \mathrm{pA}$ hyperpolarizing pulse was quantified to estimate $I_{\mathrm{h}}$ voltage deflection. Calibration: $5 \mathrm{mV}, 100 \mathrm{~ms}$. $\boldsymbol{F}$, Bar plot for showing the percentage of sag produced due to $I_{\mathrm{h}}$ voltage deflection for WT older and $\mathrm{KO}$ older animals ( $n=10$ cells for both WT and KO older animals). There was no significant difference in sag due to $I_{\mathrm{h}}$ current $(p=0.91$, Wilcoxon rank sum test). G, Representative traces showing XE991-sensitive M current for WT older (black) and KO older (gray) animals. The traces were plotted by finding the difference between pre- and postblocker current trace for an input step from -20 to $-80 \mathrm{mV}$. Calibration: 
continued

$100 \mathrm{pA}, 200 \mathrm{~ms}$. $\boldsymbol{H}$, Line plot showing the $\mathrm{I}-\mathrm{V}$ curve of XE 991-sensitive M current. There is no significant difference in the M currents between WT older (filled black circles) and KO older (gray diamond) animals for any of the input steps ( $n=19$ cells for both WT and KO, $F_{(1,258)}=2.54, p=0.11$ between WT and KO; two-way ANOVA, error bars represent the SEM). $* * p<0.01, * p<0.05$.

(Fig. 5G). We found no significant differences in $M$ currents between WT and KO CA1 cells. (mean M current for step $-80 \mathrm{mV}$ for WT, $-40.9 \pm 6.33, n=19$ cells; mean $\mathrm{M}$ current for step $-80 \mathrm{mV}$ for $\mathrm{KO}, 45.94 \pm 6.87, n=19$ cells; $F_{(1,258)}=2.54, p=0.11$ between WT and $\mathrm{KO}$; two-way ANOVA, $t$ test with Bonferroni correction; Fig. $5 H)$. Overall, these observations suggest that neither $I_{\mathrm{h}}$ voltage sag nor $M$ currents contribute to the observed elevation in $\mathrm{mAHP}$ in $\mathrm{KO}$ animals.

\section{SK currents are elevated in older KO animals compared with WT}

SK currents are also known to contribute substantially to mAHP (Sah and Clements, 1999; Stocker et al., 1999). It has also been shown that $\mathrm{Ca}^{2+}$ influx from VGCCs is elevated in FXS cells (Deng et al., 2011, 2013), indicating elevated $\mathrm{Ca}^{2+}$ levels intracellularly and hence increased SK channel activation. Thus, we hypothesized that SK currents are elevated in FXS cells, leading to the observed elevated mAHP in these cells. To test this, we used a procedure from the study by Carlen (1997). Outward currents were evoked using step depolarization of the cell from -55 to $+5 \mathrm{mV}$ and above (Fig. $6 A, B$ ), in voltageclamp mode. Apamin was bath applied to obtain postapamin perfusion trace. The difference in current before and after apamin perfusion was quantified as SK currents. These currents were significantly higher in $\mathrm{KO}$ animals compared with WT animals for the adult age group (SK current for older WTs at $+15 \mathrm{mV}$ step, $54.2 \pm 9, n=13$ cells; SK current for older KOs at $+15 \mathrm{mV}$ step, $131.73 \pm$ $25.5, n=13$ cells; $F_{(1,240)}=33.3, p<0.001$ between WTs and KOs, two-way ANOVA, $t$ test with Bonferroni correction; Fig. 6C). However, this phenotype was seen only in adult WT versus adult KO animals. When similar experiments were performed in juveniles of both genotypes, there was no significant difference in SK currents (SK current for younger WTs at $+15 \mathrm{mV}$ step, $61.93 \pm 11.9, n$ $=11$ cells; SK current for younger $\mathrm{KOs}$ at $+15 \mathrm{mV}$ step, $51.2 \pm 8.9, n=9$ cells; $F_{(1,189)}=0.51, p=0.5$ between WTs and KOs; two-way ANOVA, $t$ test with Bonferroni correction; Fig. 6D). To delineate the developmental change in SK channels levels between WT and KO animals, comparisons were made within the same genotype between different age groups. There was no significant change in the levels of SK currents with age for WT animals (SK current for older WTs at $+15 \mathrm{mV}$ step, $54.2 \pm$ $9, n=13$ cells; SK current for younger WTs at $+15 \mathrm{mV}$ step, $61.93 \pm 11.9, n=11$ cells; $F_{(1,229)}=0.01, p=0.9$ between WTs and KOs; two-way ANOVA, $t$ test with Bonferroni correction; Fig. 6E). On the contrary there was a significant increment in levels of SK currents for $\mathrm{KO}$ animals as they progressed from juvenile to adult stage (SK current for older KOs at $+15 \mathrm{mV}$ step, $131.73 \pm$ $25.5, n=13$ cells; SK current for younger KOs at +15 $\mathrm{mV}$ step, $51.2 \pm 8.9, n=9$ cells; $F_{(1,209)}=21.02, p<$
0.001 between WTs and KOs; two-way ANOVA, $t$ test with Bonferroni correction; Fig. 6F). Together, these observations show that there is an increase in the levels of SK currents with age in $\mathrm{KO}$ animals, and we note that this correlates with the worsening of spike reliability between adult and juvenile $\mathrm{KO}$ animals, as described in Figure 3.

\section{SK channel expression is unchanged in CA1 and CA3 regions for $\mathrm{KO}$ compared with WT animals}

We have observed that SK current levels are elevated in KO CA1 cells compared with WT cells (Fig. 6). This elevation might arise due to an increase in the levels of SK channels or due to a change in SK channel kinetics. The latter might arise due to a change in the kinetics of the SK channel itself or due to changes in the activity of other channels that have an effect on SK channels. The putative candidates might be $\mathrm{Ca}^{2+}$ channels known to be affected in FXS (Meredith et al., 2007; Ferron et al., 2014; Brown et al., 2001; Contractor et al., 2015). Previous published results have not shown SK channels to be targets of FMRP for transcription regulation, decreasing the likelihood that the levels will be affected in the CA1 region (Darnell et al., 2011; Deng et al., 2019). To specifically test this point, immunofluorescence experiments were used to assess the expression of SK channels. We performed in situ immunolabeling to measure the intensity of the SK2 isoform in CA3 and CA1 regions of the hippocampus using a specific antibody (Materials and Methods; Fig. 7A). We analyzed levels of SK2 protein in different regions and subsections of the hippocampus for both WT and KO animals. Similar experiments were performed on both old (adult) and young (juvenile) slices. In young animals, we have seen an increased number of spikes in CA3 with no significant change in CA1 (Fig. 4). However, the levels of SK2 protein were not significantly altered in $\mathrm{KO}$ slices for either CA3 ( $N=4$ animals for WTs; $N=4$ animals for KOs; $F_{(1,24)}=0.48, p=0.5$ for WT vs $\mathrm{KO}$ for CA3; two-way ANOVA, Sidak's post hoc test; Fig. 7B) or CA1 ( $N=4$ animals for WTs; $N=4$ animals for KOs; $F_{(1,24)}=0.21, p$ $=0.6$ for WT vs KO cells for CA1; two-way ANOVA, Sidak's post hoc test; Fig. 7C). For old animals, we have seen a reduction in spike number in the CA1 region (Fig. $3 G, L)$, but no changes in SK2 levels could be found in either CA1 or CA3 (CA1: $N=4$ animals for WTs; $N=4$ animals for KOs; $F_{(1,24)}=0.25, p=0.61$ for WT vs KO for CA1; two-way ANOVA, Sidak's post hoc test; Fig. 7E; CA3: $N=4$ animals for WTs; $N=4$ animals for $K O s ; F_{(1,24)}$ $=0.3 ; p=0.6$ for WT vs KO for CA3; two-way ANOVA, Sidak's post hoc test; Fig. 7D). Overall, these labeling studies suggest that the KO does not affect SK expression in either CA1 or CA3. The latter observation is in agreement with previous results (Deng et al., 2019). 
A wT pre and post apamin

B

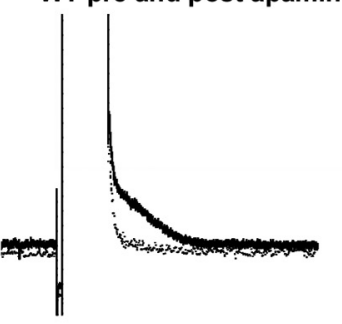

$-5 \overline{\mathrm{mV}} \overleftarrow{-65 \mathrm{mV}}^{+5 \mathrm{mV}}$

C
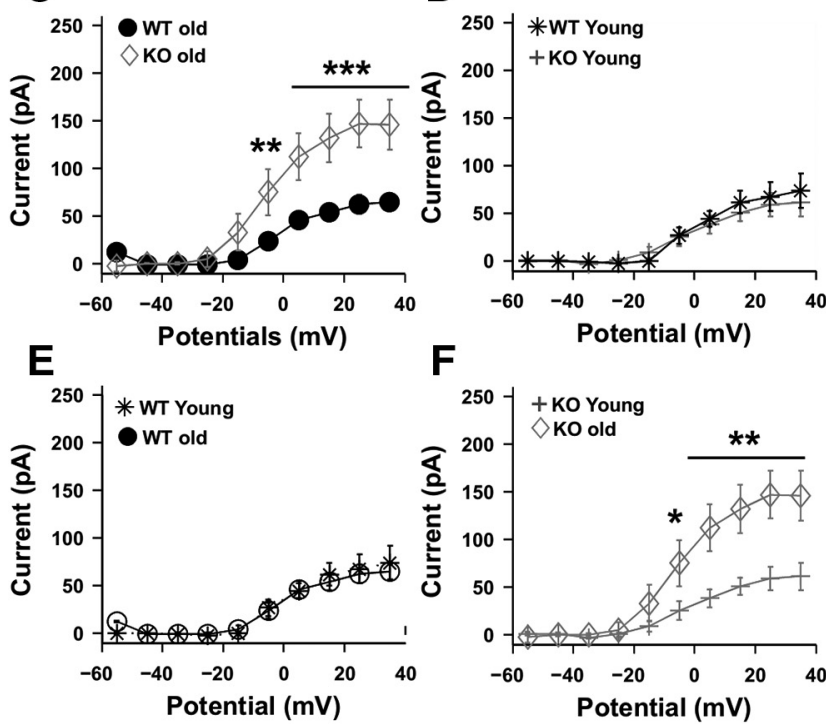

Figure 6. Apamin-sensitive SK currents are elevated in KO neurons compared with WT neurons. $\boldsymbol{A}, \boldsymbol{B}$, Representative traces showing the outward currents elicited by step depolarization voltage commands in voltage-clamp mode, for WT neuron (black; $\boldsymbol{A}$ ) and for KO neuron (gray), pre-apamin (solid line) and post-apamin (dotted line) perfusion $(\boldsymbol{B})$. Trace below indicates command voltage protocol. Calibration: $150 \mathrm{pA}, 1 \mathrm{~s}$. C, I-V curve of the apamin-sensitive current elicited across multiple steps for WT older cells ( $n=13$ cells, filled black circles) and KO older cells ( $n=13$ cells, gray diamond). Currents are significantly elevated for KO cells compared with WT cells, for multiple steps $\left(F_{(1,240)}=33.3, p<0.001\right.$ between $\mathrm{WT}$ and $\mathrm{KO}$, two-way ANOVA, error bars represent the SEM). $D, I-V$ curve of the apamin-sensitive current elicited across multiple steps in WT younger cells ( $n=11$ cells, black star) and KO younger cells ( $n$ $=9$ cells, gray plus). Currents between $\mathrm{KO}$ and WT cells at this age group were not significantly different $\left(F_{(1,189)}=0.51 ; p=0.5\right.$; two-way ANOVA, error bars represent the SEM). E, I-V curve of the apamin-sensitive current elicited across multiple steps for WT younger cells ( $n=11$ cells, black stars) and WT older cells ( $n$ $=13$ cells, black circles). There is no age-dependent change in SK currents for WT animals $\left(F_{(1,229)}=0.01, p=0.9\right.$; two-way ANOVA, error bars represent the SEM). $\boldsymbol{F}, I-V$ curve of the apamin-sensitive current elicited across multiple steps for $\mathrm{KO}$ younger cells ( $n=9$ cells, gray plus) and KO older cells $(n=13$ cells, gray diamonds). There is an age-dependent increase in SK currents in $\mathrm{KO}$ animals $\left(F_{(1,209)}=21.02, p<0.001\right.$; two-way ANOVA, bars represent the SEM). $* * * p<0.001, * * p<0.01, * p<0.05$.

\section{Apamin partially rescues the phenotype of increased variability in $\mathrm{KO}$ animals}

Having shown that elevated and variable SK currents play a role in cellular firing variability, we then asked whether blockage of the SK current might rescue the phenotype of increased variability. We observed that WT and KO populations responded differently on blocking SK currents using apamin. In WT cells, the mean of within-cell variability $\left(\mathrm{CV}_{w}\right)$ between trials increased $\left(\mathrm{CV}_{w}\right.$ for WT cells pre-apamin perfusion, $0.03 \pm 0.002, n=13$ cells; $\mathrm{CV}_{w}$ for WT cells post-apamin perfusion, $0.04 \pm 0.005, n=13$ cells; Fig. $8 A, B, E)$. However, for $\mathrm{KO}$ cells, the mean of within-cell variability $\left(\mathrm{CV}_{w}\right)$ between trials decreased $\left(\mathrm{CV}_{w}\right.$ for $\mathrm{KO}$ cells pre-apamin perfusion, $0.06 \pm 0.008, n=13$ cells; $\mathrm{CV}_{w}$ for $\mathrm{KO}$ cells post-apamin perfusion, $0.05 \pm$ $0.009, n=13$ cells; Fig. $8 C, D, E)$. Apamin treatment had no significant effect on within-cell variability $\left(\mathrm{CV}_{w}\right)$ for either WT or KO. However, it leads to a partial rescue such that post-apamin perfusion $\mathrm{KO} \mathrm{CV}_{w}$ values were not significantly different from pre-apamin perfusion WT $\mathrm{CV}_{w}$ values. A complete rescue by apamin would have resulted in a significant reduction of the $\mathrm{CV}_{w}$ of $\mathrm{KO}$ cells (which did not happen) as well as a convergence of variability between KO and WT cells (which did) $\left(F_{(1,49)}=0, p=0.96\right.$ for the effect of apamin perfusion; $F_{(1,48)}=8.74, p=0.005$ for WT and KO differences; two-way ANOVA, $t$ test with Bonferroni correction; Fig. 8E). We performed similar analysis for between-cell $\left(\mathrm{CV}_{b}\right)$ variability. Apamin perfusion led to a partial rescue in the $\mathrm{CV}_{b}$ parameter as well, such that there was a significant reduction in the $C_{b}$ of $\mathrm{KO}$ cells on apamin perfusion, but no convergence of variability between WT and KO cells $\left(\mathrm{CV}_{b}\right.$ for WT cells pre-apamin perfusion, $0.413 \pm 0.002 ; \mathrm{CV}_{b}$ for WT cells post-apamin perfusion, $0.414 \pm 0.003 ; \mathrm{CV}_{b}$ for $\mathrm{KO}$ cells pre-apamin perfusion, $0.47 \pm 0.003 ; \mathrm{CV}_{b}$ for $\mathrm{KO}$ cells post-apamin perfusion, $0.43 \pm 0.002 ; F_{(1,96)}=157.5, p<$ 0.001 for WT and KO differences; $F_{(1,96)}=53.1 ; p<0.001$ for effect of apamin on $\mathrm{CV}_{b \text {; }}$ two-way ANOVA, $t$ test with Bonferroni correction; Fig. $8 F)$. $\mathrm{CV}_{s 500}$ also showed a partial rescue with apamin perfusion $\left(\mathrm{CV}_{s 500 \_w T}\right.$ preapamin perfusion, $0.15 \pm 0.02 ; \mathrm{CV}_{\text {s500_wT }}$ post-apamin perfusion, $0.16 \pm 0.02 ; \mathrm{CV}_{\text {s500_ko }}$ pre-apamin perfusion, $0.35 \pm 0.06 ; \mathrm{CV}_{\text {s500 ko }}$ post-apamin perfusion, $0.21 \pm$ $0.04 ; F_{(1,49)}=9.63 ; p=0.003$ for WT and KO differences; $F_{(1,49)}=2.87, p=0.09$ for effect of apamin; two-way ANOVA, $t$ test with Bonferroni correction; Fig. 8G). However, the jitter slope analysis was not able to recapitulate the rescue effects (jitter slope for WT cells pre-apamin perfusion, $0.04 \pm 0.007$; jitter slope for WT cells postapamin perfusion, $0.04 \pm 0.006$; jitter slope for $\mathrm{KO}$ cells pre-apamin perfusion, $0.09 \pm 0.03$; jitter slope for $\mathrm{KO}$ cells post-apamin perfusion, $0.04 \pm 0.007 ; F_{(1,41)}=2.1 ; p$ $=0.15$ for effect of apamin; $F_{(1,41)}=3.6 ; p=0.06$ for WT and KO differences; two-way ANOVA, $t$ test with Bonferroni correction (Fig. $8 H$ ). Overall, we find that the blockage of SK currents by apamin partially rescues the variability phenotypes, which is consistent with our interpretation that the elevation in SK currents has a role in variability. 

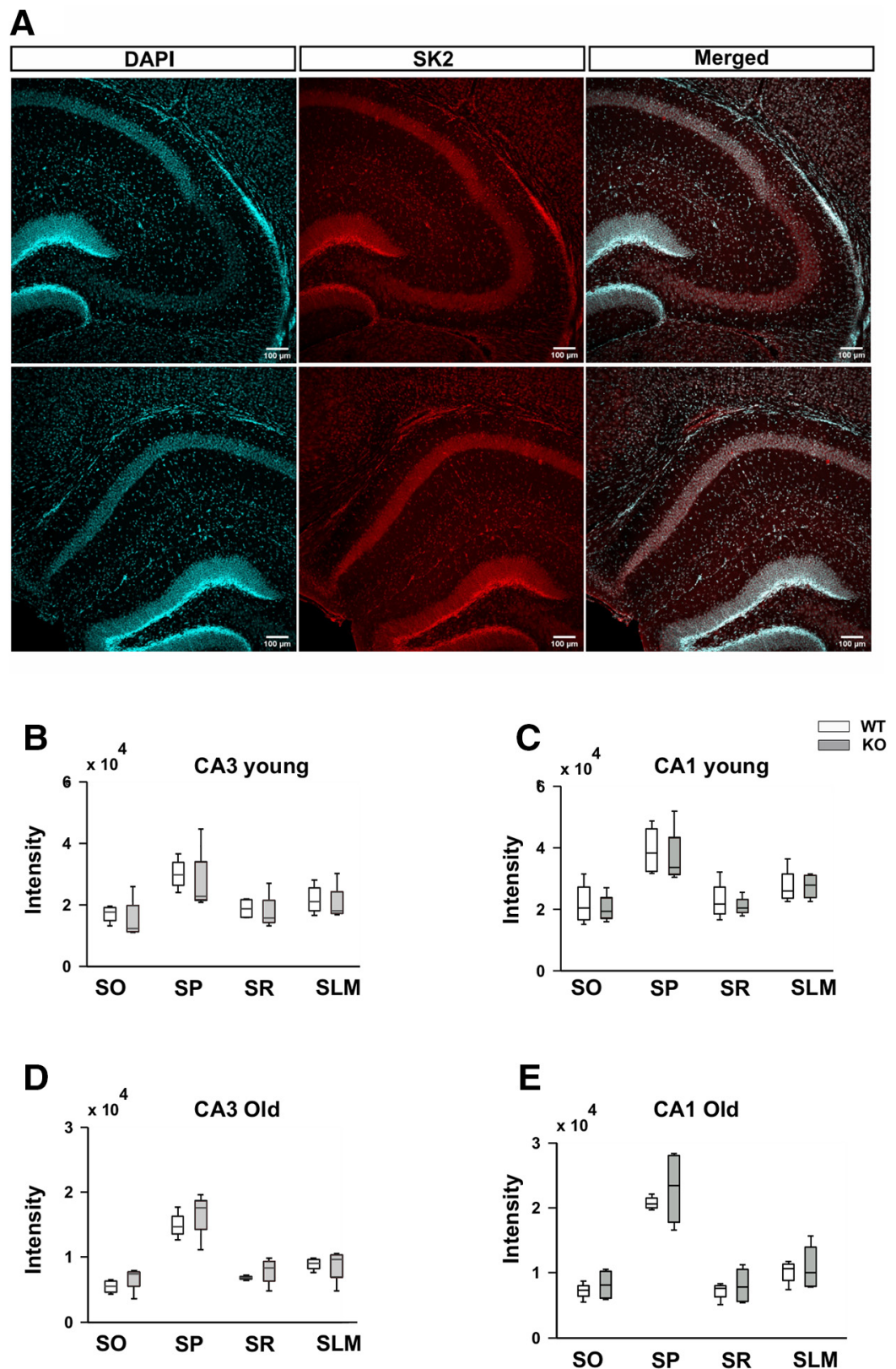

Figure 7. There is no significant change in SK2 channel levels in KO compared with WT animals. A, Representative images of SK2 labeling in CA3 (top) and CA1 (bottom) for a WT animal. Green false color was used for DAPI for better visualization. Scale bar, $100 \mu \mathrm{m}$. B. Analyzed box plot for mean intensity of SK2 channel in CA3 for young animals $(N=4$ animals for WT; $N=4$ animals for $\mathrm{KO} ; F_{(1,24)}=0.48 ; p=0.5$ between WT and KO; two-way ANOVA, error bars represent SEM). $\boldsymbol{C}$, Analyzed box plot for mean intensity of SK2 channel in CA1 for young animals. $\left(N=4\right.$ animals for WT; $N=4$ animals for $\mathrm{KO} ; F_{(1,24)}=0.21 ; p=$ 0.6 between WT and KO for CA1; two-way ANOVA, error bars represent the SEM). $\boldsymbol{D}$, Analyzed box plot for the mean intensity of SK2 channel in CA3 for old animals $\left(N=4\right.$ animals for WT; $N=4$ animals for $\mathrm{KO} ; F_{(1,24)}=0.3 ; p=0.6$ between WT and KO for CA1; two-way ANOVA, error bars represent the SEM). $\boldsymbol{E}$, Analyzed box plot for mean intensity of the SK2 channel in CA1 for old animals $\left(N=4\right.$ animals for WT; $N=4$ animals for KO; $F_{(1,24)}=0.25 ; p=0.61$ between WT and KO for CA1; two-way ANOVA, error bars represent the SEM).

\section{Blocking calcium has no rescue affect}

From the above observations, blocking SK currents led to only a partial rescue in the phenotype of increased imprecision and unreliability for spikes in KO cells. We therefore asked whether $\mathrm{Ca}^{2+}$, as an upstream modulator of SK, could also contribute to a partial rescue. To do this, we used BAPTA to chelate intracellular $\mathrm{Ca}^{2+}$. We added
BAPTA (10 mm) into the intracellular recording pipette and assessed spike precision 10 min after patching. We found that chelating calcium using BAPTA led to a further increase in spike variability instead of rescue. Spike reliability within cell was measured $\left(\mathrm{CV}_{w}\right)$ in these experiments, and it was found that spikes became significantly more variable post-BAPTA administration than pre-BAPTA for 
A
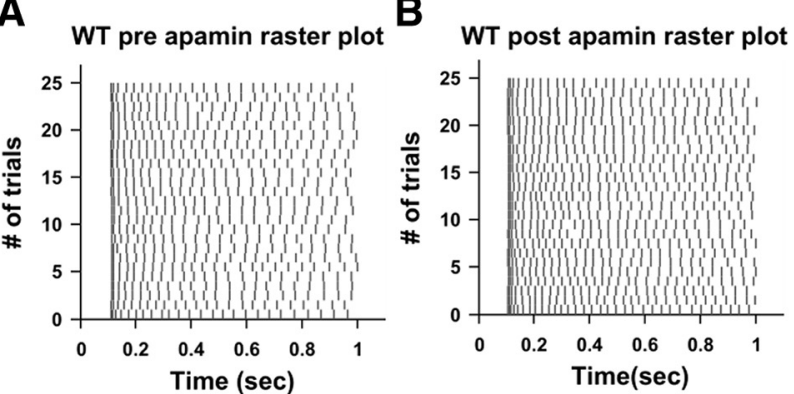

C KO pre apamin raster plot
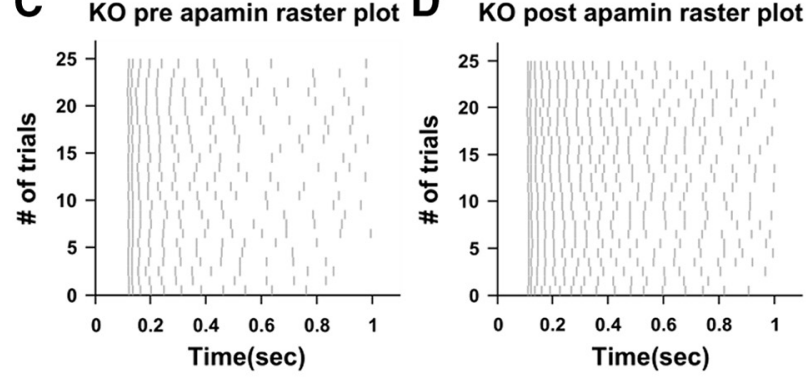

E

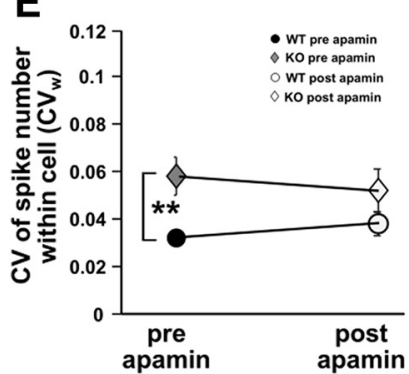

$\mathbf{F}$

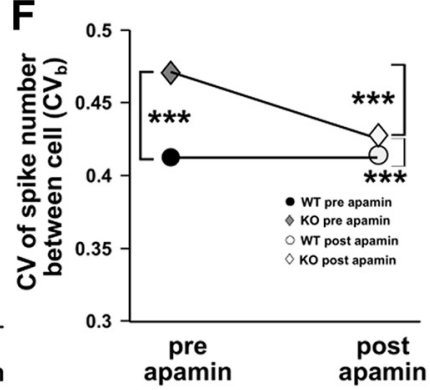

G

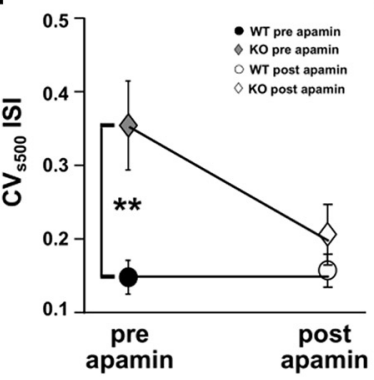

H

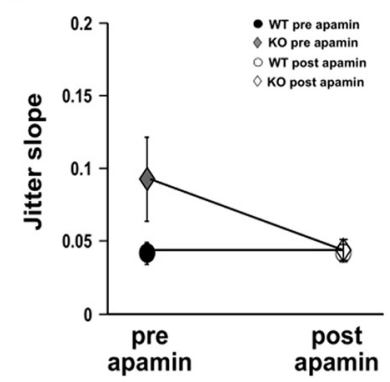

I

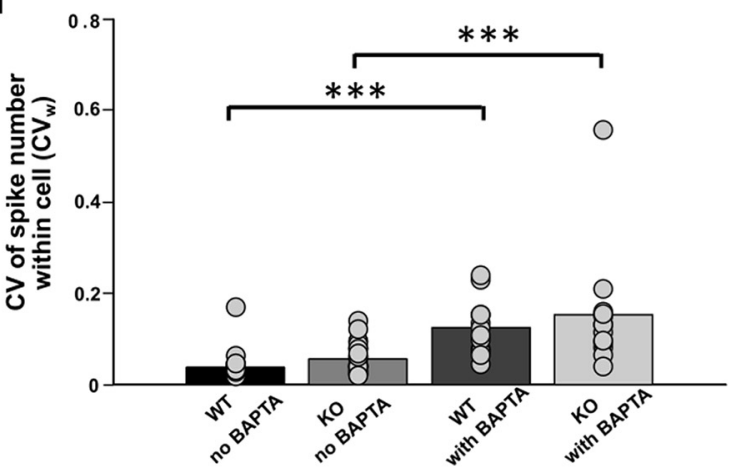

Figure 8. Partial rescue of within-cell variability $\left(\mathrm{CV}_{w}\right)$, betweencell variability $\left(\mathrm{CV}_{b}\right)$, and spike imprecision $\left(\mathrm{CV}_{s 500}\right)$ in $\mathrm{KO}$ neurons on apamin perfusion. $\boldsymbol{A}$, Representative raster plot showing spiking for step depolarization protocol for WT, pre-apamin per-
Figure 8. continued

fusion. B, Representative raster plot showing spiking for step depolarization protocol for WT, post-apamin perfusion. Same cell as in $\boldsymbol{A}$. $\boldsymbol{C}$, Representative raster plot showing spiking for step depolarization protocol for KO, pre-apamin perfusion. $\boldsymbol{D}$, Representative raster plot showing spiking for step depolarization protocol for KO, post-apamin perfusion. Same cell as in $\boldsymbol{C}$. $\boldsymbol{E}$, Change in within-cell variability parameter $\left(\mathrm{CV}_{w}\right)$ for preapamin (filled black circle) and post-apamin perfusion in WT ( $n=$ 13 cells, empty black circle) and in $\mathrm{KO}(n=13$ cells, filled gray diamond for pre-apamin perfusion and empty gray diamond for post-apamin perfusion). There is a partial rescue in $\mathrm{CV}_{w}$ parameter post-apamin perfusion for $\mathrm{KO}$ cells versus WT cells $\left(F_{(1,48)}=\right.$ 0.96 for effect of apamin; $F_{(1,48)}=0.004$ for WT and KO differences; two-way ANOVA, error bars represent the SEM). $\boldsymbol{F}$, Plot showing change in between-cell variability parameter $\left(\mathrm{CV}_{b}\right)$ for pre-apamin perfusion and post-apamin perfusion WT $(n=13$ cells, filled black circle for pre-apamin perfusion and empty black circle for post-apamin perfusion) and for pre-apamin perfusion and post-apamin perfusion $\mathrm{KO}(n=13$ cells, filled gray diamond for pre-apamin perfusion and empty gray diamond for postapamin perfusion). There is a partial rescue in $\mathrm{CV}_{b}$ parameter for KO cells versus WT cells $\left(F_{(1,96)}=157.5 ; p<0.001\right.$ for WT and $\mathrm{KO}$ differences; $F_{(1,96)}=53.1 ; p<0.001$ for effect of apamin on $\mathrm{CV}_{b}$; two-way ANOVA, error bars represent the SEM). G, Plot for $\mathrm{CV}_{s 500}$ for ISI, a measure of spike precision for pre-apamin perfusion and post-apamin perfusion WT $(n=13$ cells, filled black circle for pre-apamin perfusion and empty black circle for post-apamin perfusion) and for pre-apamin perfusion and postapamin perfusion $\mathrm{KO}(n=13$ cells, filled gray diamonds for pre apamin and empty gray diamonds for post apamin). There is a partial rescue of $\mathrm{CV}_{s 500}$ parameter on apamin perfusion $\left(F_{(1,49)}=\right.$ 9.63; $p=0.003$ for WT and KO differences; $F_{(1,49)}=2.87 ; p=$ 0.09 for effect of apamin; two-way ANOVA, error bars represent the SEM). $\boldsymbol{H}$, Plot for jitter slope, a measure of spike precision for pre-apamin perfusion and post-apamin perfusion WT $(n=13$ cells, filled black circle for pre-apamin perfusion and empty black circle for post-apamin perfusion) and for pre-apamin perfusion and postapamin perfusion $\mathrm{KO}(n=13$ cells, filled gray diamonds for pre apamin and empty gray diamonds for post apamin). The jitter slope analysis did not report a significant difference in spike imprecision for WT versus $\mathrm{KO}$ cells $\left(F_{(1,41)}=3.63 ; p=0.06\right.$ for WT and $\mathrm{KO}$ differences; $F_{(1,41)}=2.12 ; p=0.15$ for effect of apamin; two-way ANOVA, error bars represent the SEM). $I$, Bar plot showing effect of BAPTA on within-cell variability $\left(\mathrm{CV}_{w}\right)$ for WT $(n=30$ cells without BAPTA and $n=12$ cells with BAPTA) and $\mathrm{KO}(n=29$ cells without BAPTA and $n=12$ cells with BAPTA). Chelating $\mathrm{Ca}^{2+}$ using BAPTA leads to a significant increase in spike variability within cell $\left(\mathrm{CV}_{w}\right)$ for both WT and $\mathrm{KO}$ cells $\left(F_{(1,81)}=2.7 ; p=0.1\right.$ for differences between WT and KO; $F_{(1,81)}=40.5 p<0.001$ for the effect of BAPTA; two-way ANOVA with replication, error bars represent the SEM). $* * * p<0.001, * * p<0.01$.

both WT and FXS cells $\left(\mathrm{CV}_{w}\right.$ for WT cells without BAPTA administration, $0.038 \pm 0.005, n=30$ cells; $\mathrm{CV}_{w}$ for WT cells with BAPTA administration, $0.12 \pm 0.02, n=12$ cells; $p<$ $0.001 ; \mathrm{CV}_{w}$ for $\mathrm{KO}$ cells without BAPTA administration, $0.057 \pm$ $0.006, n=29$ cells; $\mathrm{CV}_{w}$ for $\mathrm{KO}$ cells with BAPTA administration, $0.16 \pm 0.04 ; F_{(1.81)}=40.5, p<0.001$ for the effect of BAPTA; two-way ANOVA, $t$ test with Bonferroni correction; Fig. 8). Since $\mathrm{Ca}^{2+}$ has a large number of ion channels as other targets, we concluded that it was not a good target for the rescue of the variability phenotype. 


\section{Discussion}

We have used a mouse model of autism, the fragile $X$ knock-out mouse, to investigate cellular correlates of autism in hippocampal CA1 pyramidal neurons. We find that the reliability of spiking is impaired in FXS adult animals. We observed an increase in spiking variability both within a cell over multiple trials and between cells in matching trials, in FXS animals. The variability appeared between 6 and 8 weeks of age, consistent with current understanding of autism as a neurodevelopmental disorder. We observed that the increased spiking variability was accompanied by reduced spiking and elevated mAHP currents. We further dissected out the channel contributions to the elevated mAHP and found that SK currents were elevated in adult FXS neurons. However, levels of SK channels were not different between WT and KO mice. To test the hypothesis that elevated SK currents are responsible for unreliable and imprecise spiking in FXS neurons, we used the specific SK blocker apamin and obtained a partial rescue of the phenotype of increased spike variability. In addition to this, we discovered a differential effect of FMRP $\mathrm{KO}$ in different hippocampal regions. In agreement with previous published results, we found that there is an increase in excitability in CA3 region of hippocampus in juvenile animals. At the same age, CA1 cells do not show any difference in excitability between WT and KO animals. As the animal becomes older, we observe that the increased excitability seen in CA3 goes away, and for CA1 cells in this age group there is an observation of reduced excitability. This is the first study that has shown that FMRP KO can lead to very different outcomes in different regions of the same brain structure, further highlighting the complexity of the disorder (Figs. 9, 10).

\section{Lowered spike reliability and spike imprecision at cellular intrinsic level in FXS KO hippocampal cells}

Our study demonstrates that there is a cell-intrinsic contribution to spiking variability in a mouse model of autism and implicates increased currents from SK channels as part of the mechanism. This finding takes significance with the failure of mGluR antagonists and blockers to significantly alleviate FXS symptoms in human patients. These findings point to the likelihood that the mGluR theory (Erickson et al., 2017) may be incomplete. Specifically, our finding of within-cell variability and between-cell variability in FXS cells shows that cells in the mutant animals may form a heterogeneous population of intrinsically variable neurons, the combined effects of which may lead to network-level incoherence.

This variability in neuronal responses over multiple trials may have implications for multiple behaviors. For example, in learning, the stimulus typically needs to be repeated over multiple trials. If the response of a cell at its intrinsic level as well as between cells is variable, the precision of input spiking as well as output activity would be reduced. This would adversely impact learning rules such as STDP and associativity (Markram et al., 1997; Bi and Poo, 1998). Further, elevated SK currents will have a direct impact on the recorded spontaneous EPSPs at the soma (Ngo-Anh et al., 2005).
A
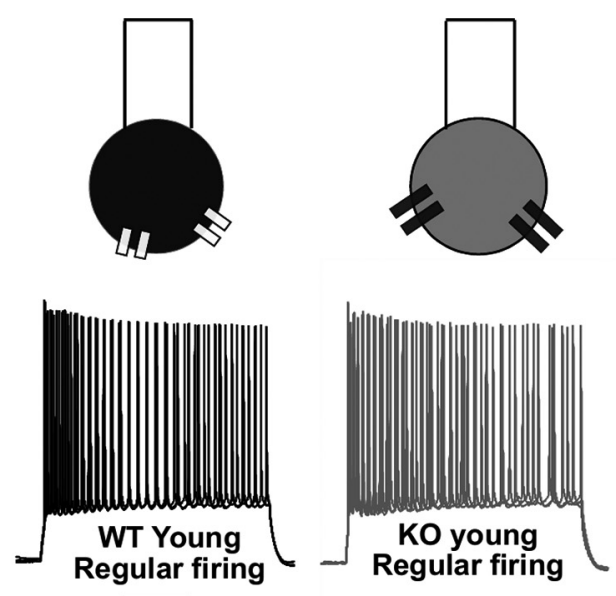

B
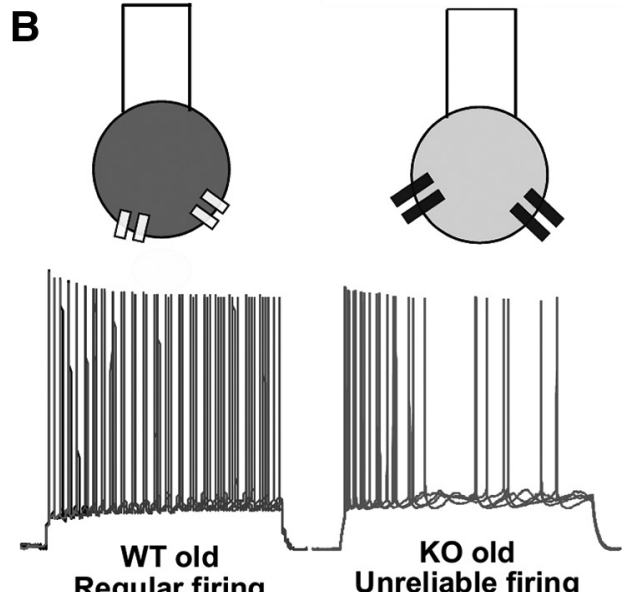

Regular firing
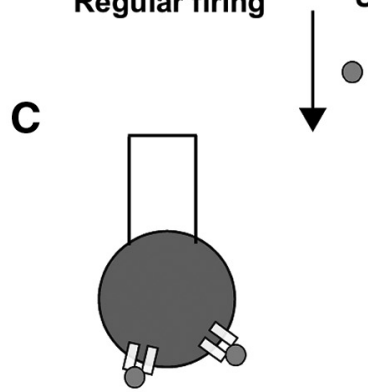

Unreliable firing
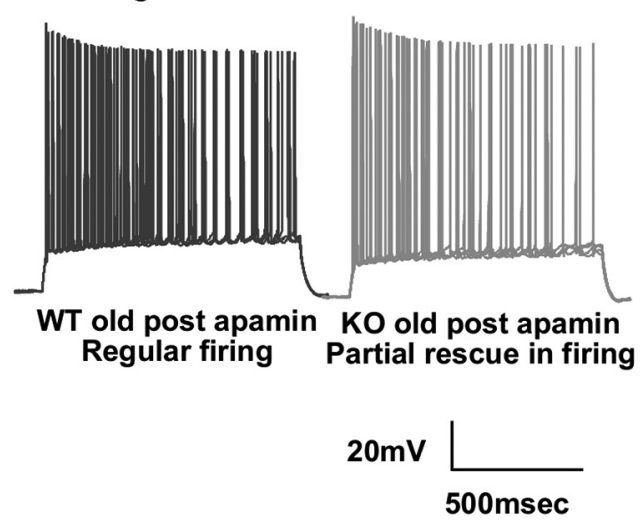

Figure 9. Schematic summary plot indicating a developmental increase in spiking variability and the role of SK channels. All spiking traces are actual raw data and show superimposed traces for four trials in WT (black) and KO (gray), respectively. $\boldsymbol{A}$, 


\section{continued}

Schematic of neurons, showing younger WT (black) and younger $\mathrm{KO}$ (gray). In young animals, we observe precise and reliable spiking across multiple trials. Calibration: $20 \mathrm{mV}, 500 \mathrm{~ms}$. $\boldsymbol{B}$, Schematic of older WT and older KO neurons. KO neurons have larger SK currents, which are represented by larger icons for SK channels. Noticeably, KO spikes are more variable and less precise, especially in the later part of the trial. C, Apamin (shown as small gray circles) is used to block SK channels present on soma. On apamin perfusion, spiking in WT (black) becomes more variable, whereas spiking in KO (light gray) increases in frequency, leading to increased spike precision and reliability.

\section{SK channel currents elevation may underlie previously observed age-dependent changes in KO cellular physiology}

FXS has many clinical and experimental attributes of a neurodevelopmental syndrome (Nimchinsky et al., 2001; Cruz-Martín et al., 2010; Meredith et al., 2012). An agedependent decline in learning has been shown in the Drosophila fragile X model (Choi et al., 2010). Theta burst stimulation (TBS) LTP has been showed to produced exaggerated LTP in anterior piriform cortex for older KO mice (12-18 months of age) but not in younger mice ( $<6$ months of age; Larson, 2005). Similar results were seen in prefrontal cortex where TBS produced a significant impairment in LTP for 12-month-old mice but not in 2-month-old animals (Martin et al., 2016). Even in humans, it has been shown that the males who have a premutation (have CGG repeats $<200$ ) predominantly demonstrated fragile $\mathrm{X}$-associated tremor/ataxia syndrome among patients who were $>50$ years old (Cornish et al., 2008). At the molecular level, an age-dependent change has also been shown in protein levels in FXS from postnatal day 17 (P17) mice to adults (Tang et al., 2015).

We observed a similar age-dependent change in the spike variability phenotype, which was absent in young $\mathrm{KO}$ animals, but manifested in older ( $>6$ weeks old) mice (Fig. 3D). Age-dependent changes in SK channels have been previously reported such that the levels of SK channels are elevated in older animals compared with younger ones (Blank et al., 2003). This complements our finding that the AHP difference between WT and KO animals arose in older animals (Fig. 5) and that the SK channel underlay the difference in the older animals. There is also evidence of age-related changes in $\mathrm{Ca}^{2+}$ levels and $\mathrm{Ca}^{2+}$ uptake mechanisms, such that basal $\mathrm{Ca}^{2+}$ levels are elevated in aging brains (Das and Ghosh, 1996; Kirischuk et al., 1996; Foster and Norris, 1997). Such altered $\mathrm{Ca}^{2+}$ levels would also have a direct impact on the functionality of SK channels. We were not able to directly investigate this possible upstream effect due to the very diverse outcomes of modulating calcium signaling (Fig. 8/).

\section{SK channels may be an FMRP target with multiple physiologic and behavioral outcomes}

FMRP targets multiple downstream pathways. It not only is a translational regulator but its $\mathrm{N}$ terminus is known to interact with multiple other proteins affecting their functioning (Brown et al., 2010; Deng et al., 2013). Thus, mutations in FMRP affect multiple aspects of cellular functioning. Previous RNA sequencing results have not shown that SK channels are elevated or affected in FXS (Brown et al., 2001; Darnell et al., 2011). However, the functioning of SK currents might be subject to other indirect effects, such as changes in calcium channel distribution, or in their functioning (Meredith et al., 2007; Ferron et al., 2014). Alterations in SK channels have substantial implications for multiple other phenotypes at the cellular and behavioral level. Previous studies have found that FXS KOs have impaired LTP in CA1 hippocampus (Lauterborn et al., 2007; Lee et al., 2011b; Tian et al., 2017). We suggest that this impairment might be partially due to elevated SK currents, which are known to shunt EPSPs and also to increase NMDA $\mathrm{Mg}^{2+}$ block (Ngo-Anh et al., 2005). Hence, our observation of elevated SK currents is consistent with the reported increase in LTP threshold in FXS (Lee et al., 2011b). These effects on LTP may have knock-on effects on memory phenotypes in FXS models. For example, a mild impairment in learning due to a change in platform location in the Morris water maze test has been found in FXS models (D'Hooge et al., 1997; Dobkin et al., 2000). SK currents have been shown to be reduced after learning, and this reduction leads to decreased variability in spiking events (Sourdet et al., 2003).

\section{Comparison with previously published studies}

Multiple previous studies have found hyperexcitability in hippocampus in FXS model mice (Deng and Klyachko, 2016; Luque et al., 2017). We do not find a strong significant difference between KO and WT f-I curves (Fig. 3/-L). However, the previously published studies were conducted in the FVB strain of mice and the present study was performed in BL/6 mice. Strain-dependent differences in FXS have previously been found (Paradee et al., 1999; Dobkin et al., 2000; Lee et al., 2011b; Routh et al., 2013). However, Brager et al. (2012) found a lowering of input resistance for KO CA1 cells indicative of reduced excitability. Telias et al. (2015) have found a phenotype similar to ours in human hippocampal culture cells. In their study, they found that FXS cells were incapable of producing multiple spikes on sustained depolarization at multiple holding potentials, similar to what we observe in this study. It is interesting to note that most excitability analyses and $f-I$ curves use 500 ms current steps, whereas in our study a difference arises after $600 \mathrm{~ms}$ and leads to a reduction in excitability in the KO (Figs. 1B, 3G). This suggests that a nuanced interpretation of such excitability studies is desirable, as the responses may have complex temporal features not reducible to a single measure of excitability. Another important point of difference is the age of the animals. Previous published studies have been performed on relatively young animals $(<\mathrm{P} 30)$ compared with the present study, where adult animals $(6-8$ weeks of age) have also been used for the experiments. Our own results (Fig. $4 B, C$ ) show that there is a substantial change in spiking variability as well as AHPs as the animal matures. Other studies have also reported an age-dependent effect of the expression of plasticity phenotypes in FXS 


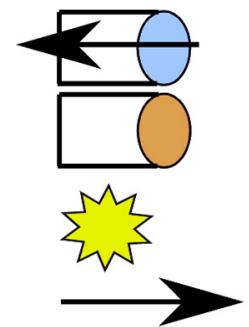

$\mathrm{Ca}^{2+}$ Channels

SK Channels

Activation

Increased Ca2+ influx

\section{CA3; Low baseline}

Young Old

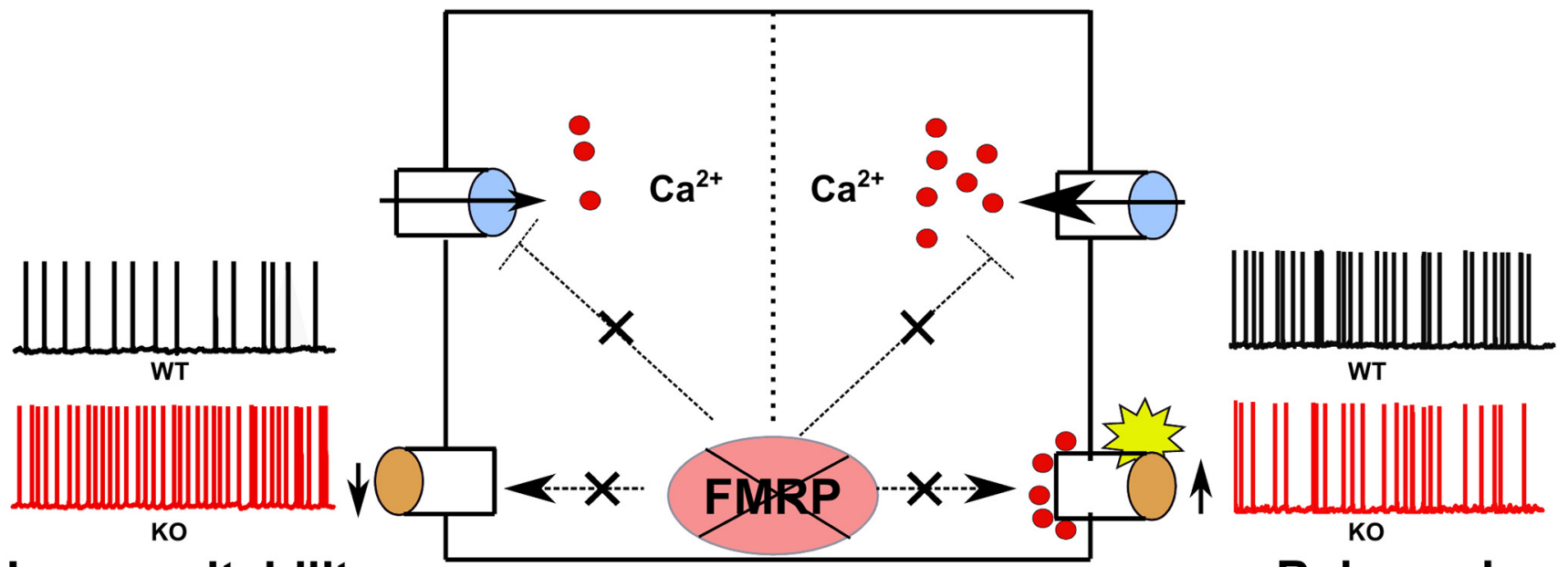

Hyperexcitability

Balanced

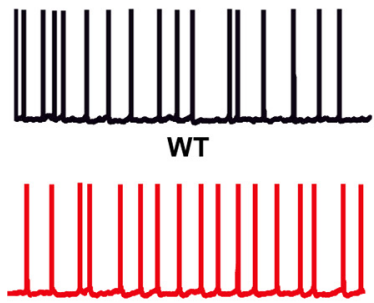

KO

Balanced

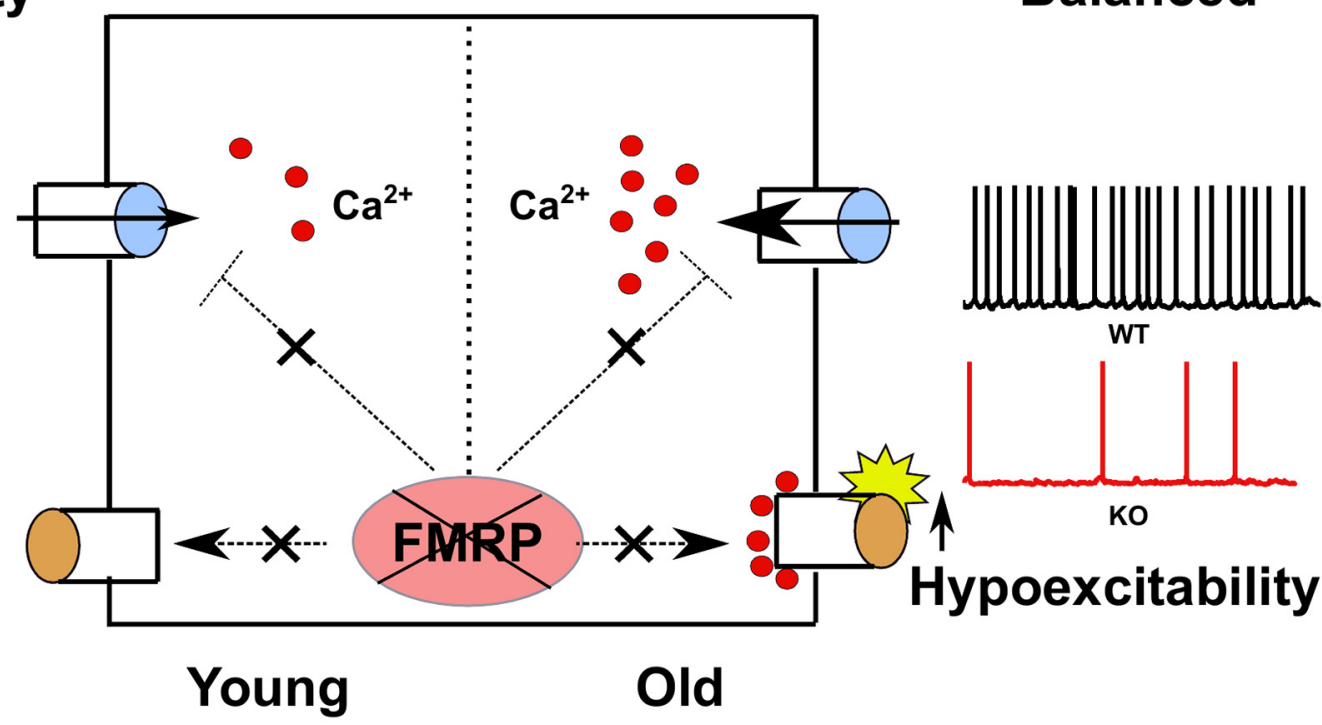

CA1; High baseline

Figure 10. Schematic of a model explaining differential effect of FMRP KO in CA3 and CA1. A, In young CA3 cells, the loss of FMRP leads to reduced activation of SK channels, which in turn gives neuronal hyperexcitability. However, as the animal matures, there is an increase in calcium influx in these cells. This compensates for this reduced SK activity seen in young CA3 cells leading to a nonsignificant change in excitability for KO cells compared with WT cells. $\boldsymbol{B}$, In young CA1 cells, both WT and KO cells start with elevated excitability as a result of which no significant differences can be seen between WT and KO. However, as the animal matures, 


\section{continued}

the increase in $\mathrm{Ca}^{2+}$ influx brings excitability down for both WT and KO. This decrease in excitability is significantly greater for KO animals as many $\mathrm{Ca}^{2+}$ channels are known to be translationally regulated by FMRP. Under the absence of FMRP, these channels are known to be elevated significantly, making KO neurons hypoexcitable compared with WT neurons.

mice (Larson, 2005; Martin et al., 2016). Fragile X syndrome is known to be a developmental disease where symptoms and many other biochemical and other pathways are known to undergo changes with the age of the animal. Hence, it may be important to factor in age dependence and possibly use a wider range of ages to re-examine some of the conclusions that have been made from FXS models.

Our study is also the first to examine the effect of variability and spiking asynchrony, which again we find to be an age-dependent effect. We postulate that variability in the firing of individual cells, which previous studies have not explicitly examined, may be a further complicating factor in analyzing baseline changes arising due to the FMRP mutation.

\section{FMRP KO has different physiologic outcomes in different regions of the hippocampus brain regions}

In the present study, we make the important and unexpected finding that FMRP $\mathrm{KO}$ has differential cellphysiologic effects on different subsections of the same brain region. In an attempt to replicate previous results, we found that there is hyperexcitability in pyramidal neurons of the CA3 region in juvenile mice, (as previously reported by Deng et al., 2019) but there was no significant difference in spiking in the CA1 region at the same age. Further, the phenotype reverses for CA1 cells in adult FMRP KO animals such that pyramidal neurons have reduced excitability, whereas for CA3 regions the hyperexcitability goes away. We suggest that these differential effects arise from the balance of effects among the direct effects of FMRP on SK channels, the indirect effects of FMRP on SK via calcium, and the effects of age, again potentially via calcium.

\section{Direct effects of FMRP on SK}

Deng et al. (2019) have shown that the absence of FMRP leads to reduced activity of SK channels. They have shown that a physical interaction between FMRP and SK leads to the activation of SK channels. This suggests that FMRP is a direct activator of SK channels. In the case of mutant animals where FMRP is absent, there is a reduction in SK currents leading to hyperexcitability, which has been observed both in the present and previous study (Fig. 10). We see this effect in CA3 cells for KO animals in the younger age group.

\section{Indirect effects on SK via calcium}

SK channels are dependent on intracellular calcium for their activation. Calcium channels are known targets of FMRP for transcription regulators (Brown et al., 2001; Darnell et al., 2011). Calcium influx via L-type $\mathrm{Ca}^{2+}$ channels are known to be elevated in neural progenitor cells (Danesi et al., 2018). Cortical culture neurons have been shown to have significantly elevated basal calcium levels in FXS neurons (Castagnola et al., 2018), and there is increased calcium influx in CA3 cells (Deng et al., 2011, 2013). In reference to human patients, multiple point mutations in $\mathrm{Ca}^{2+}$ genes are associated with autism (Contractor et al., 2015; Pinggera et al., 2015; Nguyen et al., 2018). There are multiple other studies in other neuron types that show increased intracellular calcium in autism models (Laumonnier et al., 2006; Krey and Dolmetsch, 2007; Tessier and Broadie, 2011; Pinggera et al., 2015; Limpitikul et al., 2016). These studies are in agreement with our observations in the present study where we see increased SK currents in CA1 cells, which is expected if the intracellular calcium levels are elevated in FXS neurons (Fig. 10). This increased calcium influx can explain the reduced excitability phenotypes seen in older CA3 and CA1 cells.

Effects of age on calcium Calcium binding proteins and intracellular calcium dynamics are known to undergo development-dependent alterations in FXS neurons (Tessier and Broadie, 2011). Calcium levels and $\mathrm{Ca}^{2+}$ uptake mechanisms are also known to undergo changes with aging in animals (Das and Ghosh, 1996; Kirischuk et al., 1996; Foster and Norris, 1997). Though there are limited studies available in reference to a change in calcium channel levels with age in autism models, we hypothesize that a change in calcium dynamics is consistent with the fact that autism is a neurodevelopment disorder (Fig. 10). We see this effect in both CA3 and CA1 regions for $\mathrm{KO}$ animals, where in CA3 the increased excitability seen in younger animals levels off as the animal becomes adult. On the other hand, because of the increase in calcium, CA1 cells in which excitability was balanced in the young age group goes in the direction of hypoexcitability in older age groups.

Based on these findings, we propose a schematic model to explain these differences (Fig. 10). In the young age group for KO CA3 cells, the absence of FMRP leads to hyperexcitability, as explained above. As the animal becomes older, this effect goes away due to increased calcium influx with age, leading to SK activation and balancing out hyperexcitability. On the other hand, for young KO CA1 cells, both WT and KO start with maximum increased excitability where it is not significantly different. As the animal becomes older, increased calcium influx moves KO cells toward hypoexcitability.

\section{Defects in single-cell physiology may lead to network and population asynchrony}

Multiple studies have shown that variability or lack of coordination in spiking exists in FXS at the network level (Arbab et al., 2018b; Talbot et al., 2018). In these tetrodebased studies, variability has been shown at the level of cellular firing patterns in the in vivo network; hence, it is difficult to separate cell-intrinsic properties from synaptic and network phenomena. In our study, we use the $\mathrm{CV}_{b}$ parameter to gain an understanding of the correlation 
between cells at a population level. Using this analysis, we have tried to estimate the variability that exists between individual neuron responses when actually neurons were recorded one at a time. In contrast to tetrode recordings or field response recordings, where the recorded response is a result of multiple neurons and hence is a population response, $\mathrm{CV}_{b}$ remains an intrinsic response of neurons depending on its active channels. $\mathrm{CV}_{b}$ is an indirect readout of network correlations and should not be inferred as giving actual network correlation information. Clear mechanisms are lacking for this reported asynchrony. However, prior researchers have postulated that synaptic mechanisms may be responsible for the observed asynchrony (Talbot et al., 2018). Our study provides an alternative hypothesis for the mechanism, namely, that the effect is cell intrinsic and is in part due to altered kinetics of SK channels. Other studies provide evidence in favor of a role for SK channels in mediating precision and synchronous firing. For example, Deister et al. (2009) showed that SK channels were responsible for mediating precision in autonomous firing in globus pallidus neurons. Schultheiss et al. (2010) showed that dendritic SK channels also control synchronization. Another study by Kleiman-Weiner et al. (2009) has shown that SK channels play a role in mediating thalamocortical oscillations. A study by Combe et al. (2018) shows that SK channels contribute to phase locking for the spiking of CA1 cells of the hippocampus to slow gamma frequency inputs from Schaffer collaterals. Thus, the alterations in SK channel kinetics in FXS mutants as established by our study might have substantial impacts on phase coding and synchronization of hippocampal cell populations.

\section{A theory of FXS pathophysiology}

An alternate theory to mGluR theory in explanation of FXS pathophysiology is the discoordination theory. The idea behind this theory is that many of the cognitive impairments seen in FXS are due to altered coordination in the spiking of cells in networks, which might be due either to an imbalance in excitation-inhibition in the networks (El Idrissi et al., 2005; Heulens et al., 2012) or to an intrinsic incoherent tendency of the neurons (Brock et al., 2002; Fenton, 2016; Radwan et al., 2016). Though this theory is preliminary, it may offer a promising alternative point of view from the traditional mGluR theory. Some studies have shown that intrinsic changes in cells during FXS affect their excitatory/inhibitory balance (Zhang et al., 2014; Lee et al., 2017) and that modulation of these channels leads to the rescue of the FXS phenotype. This present study has probed the dysfunction of a specific ion channel, SK, which was shown to affect the spiking variability at the single-cell level. It is an addition to the increasing list of ion channels that are known to be affected in FXS and may have an important effect on FXS etiology.

\section{References}

Arbab T, Battaglia FP, Pennartz CMA, Bosman CA (2018a) Abnormal hippocampal theta and gamma hypersynchrony produces network and spike timing disturbances in the Fmr1-KO mouse model of fragile X syndrome. Neurobiol Dis 114:65-73.
Arbab T, Pennartz CMA, Battaglia FP (2018b) Impaired hippocampal representation of place in the Fmr1-knockout mouse model of fragile X syndrome. Sci Rep 8:8889.

Bacci A, Huguenard JR (2006) Enhancement of spike-timing precision by autaptic transmission in neocortical inhibitory interneurons. Neuron 49:119-130.

Bi G, Poo M (1998) Synaptic modifications in cultured hippocampal neurons: dependence on spike timing, synaptic strength, and postsynaptic cell type. J Neurosci 18:10464-10472.

Blank T, Nijholt I, Kye MJ, Radulovic J, Spiess J (2003) Smallconductance, Ca2+-activated $\mathrm{K}+$ channel SK3 generates agerelated memory and LTP deficits. Nat Neurosci 6:911-912.

Brager DH, Akhavan AR, Johnston D (2012) Impaired dendritic expression and plasticity of h-channels in the fmr1-/y mouse model of fragile X syndrome. Cell Rep 1:225-33.

Brock JON, Brown CC, Boucher J (2002) The temporal binding deficit hypothesis of autism. Dev Psychopathol 14:209-224.

Brown MR, Kronengold J, Gazula VR, Chen Y, Strumbos JG, Sigworth FJ, Navaratnam D, Kaczmarek LK (2010) Fragile X mental retardation protein controls gating of the sodium-activated potassium channel Slack. Nat Neurosci 13:819-21.

Brown V, Jin P, Ceman S, Darnell JC, Donnell WTO, Tenenbaum SA, JX, Feng Y, Wilkinson KD, Keene JD, Darnell RB, Warren ST (2001) Microarray identification of FMRP-associated brain mRNAs and altered mRNA translational profiles in fragile $X$ syndrome. Cell 107:477-487.

Carandini M (2004) Amplification of trial-to-trial response variability by neurons in visual cortex. PLoS Biol 2:E264.

Carlen PL (1997) Reversible inhibition of I K, I AHP, I h and I Ca currents by internally applied gluconate in rat hippocampal pyramidal neurones. Pflugers Arch 433:343-350.

Castagnola S, Delhaye S, Folci A, Paquet A, Brau F, Duprat F, Jarjat M, Grossi M, Béal M (2018) New insights into the role of Cav2 protein family in calcium flux deregulation in Fmr1-KO neurons. Front Mol Neurosci 11:1-13.

Choi $\mathrm{CH}$, McBride SMJ, Schoenfeld BP, Liebelt DA, Ferreiro D, Ferrick NJ, Hinchey $P$, Kollaros $M$, Rudominer RL, Terlizzi AM, Koenigsberg E, Wang Y, Sumida A, Nguyen HT, Bell AJ, McDonald TV, Jongens TA (2010) Age-dependent cognitive impairment in a Drosophila Fragile $X$ model and its pharmacological rescue. Biogerontology 11:347-362.

Combe CL, Canavier CC, Gasparini S (2018) Intrinsic mechanisms of frequency selectivity in the proximal dendrites of CA1 pyramidal neurons. J Neurosci 38:8110-8127.

Contractor A, Klyachko VA, Portera-Cailliau C (2015) Altered neuronal and circuit excitability in fragile $X$ syndrome. Neuron 87:699715.

Cornish KM, Li L, Kogan CS, Jacquemont S, Turk J, Dalton A, Hagerman RJ, Hagerman PJ (2008) Age-dependent cognitive changes in carriers of the fragile $X$ syndrome. Cortex 44:628-636.

Crook SM, Ermentrout GB, Bower JM (1998) Spike frequency adaptation affects the synchronization properties of networks of cortical oscillators. Neural Comput 10:837-854.

Cruz-Martín A, Crespo M, Portera-Cailliau C (2010) Delayed stabilization of dendritic spines in fragile X mice. J Neurosci 30:77937803.

Cudmore RH, Fronzaroli-Molinieres L, Giraud P, Debanne D (2010) Spike-time precision and network synchrony are controlled by the homeostatic regulation of the D-type potassium current. J Neurosci 30:12885-12895.

Danesi C, Achuta VS, Corcoran P, Peteri U, Turconi G (2018) Increased calcium influx through L-type calcium channels in human and mouse neural progenitors lacking fragile $\mathrm{X}$ mental retardation protein. Stem Cell Rep 11:1449-1461.

Darnell JC, Driesche SJ, Van Zhang C, Hung YK, Mele S, Fraser A, Stone CE, Chen EF, Fak C, Chi JJ, Licatalosi SW, Richter DD, Darnell JD, RB (2011) FMRP stalls ribosomal translocation on mRNAs linked to synaptic function and autism. Cell 146:247-261.

Das N, Ghosh S (1996) The effect of age on calcium dynamics in rat brain in vivo. Mech Ageing Dev 88:17-24. 
Deister CA, Chan CS, Surmeier DJ, Wilson CJ (2009) Calciumactivated SK channels influence voltage-gated ion channels to determine the precision of firing in globus pallidus neurons. $J$ Neurosci 29:8452-8461.

Deng PY, Klyachko VA (2016) Increased persistent sodium current causes neuronal hyperexcitability in the entorhinal cortex of Fmr1 knockout mice. Cell Rep 16:3157-3166.

Deng PY, Sojka D, Klyachko VA (2011) Abnormal presynaptic shortterm plasticity and information processing in a mouse model of fragile X syndrome. J Neurosci 31:10971-10982.

Deng PY, Rotman Z, Blundon JA, Cho Y, Cui J, Cavalli V, Zakharenko SS, Klyachko VA (2013) FMRP regulates neurotransmitter release and synaptic information transmission by modulating action potential duration via BK channels. Neuron 77:696-711.

Deng PY, Carlin D, Oh YM, Myrick LK, Warren ST, Cavalli V, Klyachko VA (2019) Voltage-independent SK channel dysfunction causes neuronal hyperexcitability in the hippocampus of Fmr1 knock-out mice. J Neurosci 39:28-43.

D'Hooge R, Nagels G, Franck F, Bakker CE, Reyniers E, Storm K, Kooy RF, Oostra BA, Willems PJ, De Deyn PP (1997) Mildly impaired water maze performance in male $\mathrm{Fmr} 1$ knockout mice. Neuroscience 76:367-376.

Dobkin C, Rabe A, Dumas R, El Idrissi A, Haubenstock H, Ted Brown W (2000) Fmr1 knockout mouse has a distinctive strain-specific learning impairment. Neuroscience 100:423-429.

El Idrissi A, Ding XH, Scalia J, Trenkner E, Brown WT, Dobkin C (2005) Decreased GABA(A) receptor expression in the seizureprone fragile $X$ mouse. Neurosci Lett 377:141-146.

Erickson CA, Davenport MH, Schaefer TL, Wink LK, Pedapati EV, Sweeney JA, Fitzpatrick SE, Brown WT, Budimirovic D, Hagerman RJ, Hessl D, Kaufmann WE, Berry-Kravis E (2017) Fragile X targeted pharmacotherapy: lessons learned and future directions. $J$ Neurodev Disord 9:1-14.

Faisal AA, Selen LPJ, Wolpert DM (2008) Noise in the nervous system. Nat Rev Neurosci 9:292-303.

Fenton AA (2016) Excitation-inhibition discoordination in rodent models of mental disorders. Biol Psychiatry 77:1079-1088.

Ferron L, Nieto-Rostro M, Cassidy JS, Dolphin AC (2014) Fragile X mental retardation protein controls synaptic vesicle exocytosis by modulating N-type calcium channel density. Nat Commun 5:3628.

Foster TC, Norris CM (1997) Age-associated changes in $\mathrm{Ca}(2+)$ dependent processes: relation to hippocampal synaptic plasticity. Hippocampus 7:602-612.

Fricker D, Miles R (2000) EPSP amplification and the precision of spike timing in hippocampal neurons. Neuron 28:559-569.

Fujisawa S, Yamada MK, Nishiyama N, Matsuki N, Ikegaya Y (2004) BDNF boosts spike fidelity in chaotic neural oscillations. Biophys $\mathrm{J}$ $86: 1820-1828$.

Gabbiani F, Dewell R (2018) M-current regulates firing mode and spike reliability in a collision detecting neuron. J Neurophysiol 120:1753-1764.

Gastrein P, Campanac É, Gasselin C, Cudmore RH, Bialowas A, Carlier E, Fronzaroli-Molinieres L, Ankri N, Debanne D (2011) The role of hyperpolarization-activated cationic current in spike-time precision and intrinsic resonance in cortical neurons in vitro. $J$ Physiol 589:3753-3773.

Gittelman JX (2006) Kv1.1-containing channels are critical for temporal precision during spike initiation. J Neurophysiol 96:12031214.

Gonçalves JT, Anstey JE, Golshani P, Portera-Cailliau C (2013) Circuit level defects in the developing neocortex of fragile $X$ mice. Nat Neurosci 16:903-909.

Gross C, Yao X, Pong DL, Jeromin A, Bassell GJ (2011) Fragile X mental retardation protein regulates protein expression and mRNA translation of the potassium channel Kv4.2. J Neurosci 31:56935698.

Guan D, Higgs MH, Horton LR, Spain WJ, Foehring RC (2011) Contributions of Kv7-mediated potassium current to sub- and suprathreshold responses of rat layer II/III neocortical pyramidal neurons. J Neurophysiol 106:1722-1733.
Han X, Boyden ES (2007) Multiple-color optical activation, silencing, and desynchronization of neural activity, with single-spike temporal resolution. PLoS One 2:e299.

Heulens I, D'Hulst C, Van Dam D, De Deyn PP, Kooy RF (2012) Pharmacological treatment of fragile $X$ syndrome with GABAergic drugs in a knockout mouse model. Behav Brain Res 229:244-249.

Hönigsperger C, Marosi M, Murphy R, Storm JF (2015) Dorsoventral differences in $\mathrm{Kv} 7 / \mathrm{M}$-current and its impact on resonance, temporal summation and excitability in rat hippocampal pyramidal cells. J Physiol 593:1551-1580.

Hou GQ, Pan X, Liao CS, Wang SH, Li DF (2012) SK channels modulate the excitability and firing precision of projection neurons in the robust nucleus of the arcopallium in adult male zebra finches. Neurosci Bull 28:271-281.

Kirischuk S, Voitenko N, Kostyuk P, Verkhratsky A (1996) Ageassociated changes of cytoplasmic calcium homeostasis in cerebellar granule neurons in situ: investigation on thin cerebellar slices. Exp Gerontol 31:475-487.

Kleiman-Weiner M, Beenhakker MP, Segal WA, Huguenard JR (2009) Synergistic roles of GABA A receptors and SK channels in regulating thalamocortical oscillations. J Neurophysiol 102:203213.

Krey JF, Dolmetsch RE (2007) Molecular mechanisms of autism: a possible role for $\mathrm{Ca} 2+$ signaling. Curr Opin Neurobiol 17:112-119.

Kwag J, Jang HJ, Kim M, Lee S (2014) M-type potassium conductance controls the emergence of neural phase codes: a combined experimental and neuron modelling study. J R Soc Interface 11: 20140604.

Larson J (2005) Age-dependent and selective impairment of longterm potentiation in the anterior piriform cortex of mice lacking the fragile X mental retardation protein. J Neurosci 25:9460-9469.

Laumonnier F, Roger S, Guérin P, Molinari F, M'rad R, Cahard D, Belhadj A, Halayem M, Persico AM, Elia M, Romano V, Holbert S, Andres C, Chaabouni H, Colleaux L, Constant J, Le Guennec JY, Briault S (2006) Association of a functional deficit of the BKCa channel, a synaptic regulator of neuronal excitability, with autism and mental retardation. Am J Psychiatry 163:1622-1629.

Lauterborn JC, Rex CS, Krama E, Chen LY, Pandyarajan V, Lynch G, Gall CM (2007) Brain-derived neurotrophic factor rescues synaptic plasticity in a mouse model of fragile $X$ syndrome. J Neurosci 27:10685-10694.

Lee E, Lee J, Kim E (2017) Excitation/inhibition imbalance in animal models of autism spectrum disorders. Biol Psychiatry 81:838-847.

Lee HY, Ge W-P, Huang W, He Y, Wang GX, Rowson-Baldwin A, Smith SJ, Jan YN, Jan LY (2011a) Bidirectional regulation of dendritic voltage-gated potassium channels by the fragile $X$ mental retardation protein. Neuron 72:1091.

Lee HY, Ge W, Huang W, He Y, Wang GX, Smith SJ, Jan YN, Jan LY (2011b) Bidirectional regulation of dendritic voltage-gated potassium channels by the fragile $\mathrm{X}$ mental retardation protein. Neuron 72:630-642.

Limpitikul WB, Dick IE, Ben-Johny M, Yue DT (2016) An autismassociated mutation in CaV1.3 channels has opposing effects on voltage- and $\mathrm{Ca} 2+-$ dependent regulation. Sci Rep 6:1-13.

Luque MA, Beltran-Matas P, Marin MC, Torres B, Herrero L (2017) Excitability is increased in hippocampal CA1 pyramidal cells of Fmr1 knockout mice. PLoS One 12:e0185067.

Madison DV, Lancaster B, Nicoll RA (1987) Voltage clamp analysis of cholinergic action in the hippocampus. J Neurosci 7:733-741.

Mainen ZF, Sejnowski TJ (1995) Reliability of spike timing in neocortical neurons. Science 268:1503-1506.

Markram H, Lübke J, Frotscher M, Sakmann B (1997) Regulation of synaptic efficacy by coincidence of postsynaptic APs and EPSPs. Science 275:213-215.

Martin HGS, Lassalle O, Brown JT, Manzoni OJ (2016) Agedependent long-term potentiation deficits in the prefrontal cortex of the Fmr1 knockout mouse model of fragile $X$ syndrome. Cereb Cortex 26:2084-2092. 
Meredith RM, Dawitz J, Kramvis I (2012) Sensitive time-windows for susceptibility in neurodevelopmental disorders. Trends Neurosci 35:335-344.

Meredith RM, Holmgren CD, Weidum M, Burnashev N (2007) Increased threshold for spike-timing-dependent plasticity is caused by unreliable calcium signaling in mice lacking fragile $X$ gene Fmr1. Neuron 54:627-638.

Ngo-Anh TJ, Bloodgood BL, Lin M, Sabatini BL, Maylie J, Adelman JP (2005) SK channels and NMDA receptors form a Ca2+mediated feedback loop in dendritic spines. Nat Neurosci 8:642649.

Nguyen RL, Medvedeva YV, Ayyagari TE, Schmunk G, Jay J (2018) Intracellular calcium dysregulation in autism spectrum disorder: an analysis of converging organelle signaling pathways. Biochim Biophys Acta Mol Cell Res Res 1865:1718-1732.

Nigro MJ, Mateos-Aparicio P, Storm JF (2014) Expression and functional roles of $\mathrm{Kv} 7 / \mathrm{KCNQ} / \mathrm{M}$-channels in rat medial entorhinal cortex layer II stellate cells. J Neurosci 34:6807-6812.

Nimchinsky EA, Oberlander AM, Svoboda K (2001) Abnormal development of dendritic spines in FMR1 knock-out mice. J Neurosci 21:5139-5146.

O'Donnell WT, Warren ST (2002) A decade of molecular studies of fragile X syndrome. Annu Rev Neurosci 25:315-338.

Orbán G, Kiss T, Erdi P (2006) Intrinsic and synaptic mechanisms determining the timing of neuron population activity during hippocampal theta oscillation. J Neurophysiol 96:2889-2904.

Paradee W, Melikian HE, Rasmussen DL, Kenneson A, Conn PJ (1999) Fragile X mouse: strain effects of knockout phenotype and evidence suggesting deficient amygdala function. Neuroscience 94:185-192.

Pfeuty B, Mato G, Golomb D, Hansel D (2003) Electrical synapses and synchrony: the role of intrinsic currents. J Neurosci 23:62806294.

Pinggera A, Lieb A, Benedetti B, Lampert M, Monteleone S, Liedl KR, Tuluc P, Striessnig J (2015) CACNA1D de novo mutations in autism calcium channels. Biol Psychiatry 77:816-822.

Radwan B, Dvorak D, Fenton AA (2016) Impaired cognitive discrimination and discoordination of coupled theta-gamma oscillations in Fmr1 knockout mice. Neurobiol Dis 88:125-138.

Routh BN, Johnston D, Brager DH (2013) Loss of functional A-type potassium channels in the dendrites of CA1 pyramidal neurons from a mouse model of fragile X syndrome. J Neurosci 33:1944219450.

Sah P, Clements JD (1999) Photolytic manipulation of [Ca2+]i reveals slow kinetics of potassium channels underlying the afterhyperpolarization in hipppocampal pyramidal neurons. J Neurosci 19:3657-3664.

Schultheiss NW, Edgerton JR, Jaeger D (2010) Phase response curve analysis of a full morphological globus pallidus neuron model reveals distinct perisomatic and dendritic modes of synaptic integration. J Neurosci 30:2767-2782.

Shah MM, Mistry M, Marsh SJ, Brown DA, Delmas P (2002) Molecular correlates of the M-current in cultured rat hippocampal neuronsn. J Physiol 544(Pt 1):29-37.

Sourdet V, Russier M, Daoudal G, Ankri N, Debanne D (2003) Longterm enhancement of neuronal excitability and temporal fidelity mediated by metabotropic glutamate receptor subtype 5 . J Neurosci 23:10238-10248.

Stevens CF, Zador AM (1998) Input synchrony and the irregular firing of cortical neurons. Nat Neurosci 1:210-217.

Stocker M, Krause M, Pedarzani P (1999) An apamin-sensitive $\mathrm{Ca} 2+$-activated $\mathrm{K}+$ current in hippocampal pyramidal neurons. Proc Natl Acad Sci U S A 96:4662-4667.

Strumbos JG, Brown MR, Kronengold J, Polley DB, Kaczmarek LK (2010) Fragile $X$ mental retardation protein is required for rapid experience-dependent regulation of the potassium channel Kv3.1b. J Neurosci 30:10263-10271.

Talbot ZN, Sparks FT, Dvorak D, Curran BM, Alarcon JM, Fenton AA (2018) Normal CA1 place fields but discoordinated network discharge in a Fmr1-null mouse model of fragile $X$ syndrome. Neuron 684-697.e4.

Tang B, Wang T, Wan H, Han L, Qin X, Zhang Y, Wang J, Yu C, Berton F, Francesconi W, Yates JR, Vanderklish PW, Liao L (2015) Fmr1 deficiency promotes age-dependent alterations in the cortical synaptic proteome. Proc Natl Acad Sci 112:E4697-E4706.

Telias M, Kuznitsov-Yanovsky L, Segal M, Ben-Yosef D (2015) Functional deficiencies in Fragile $X$ neurons derived from human embryonic stem cells. J Neurosci 35:15295-15306.

Tessier CR, Broadie K (2011) The fragile X mental retardation protein developmentally regulates the strength and fidelity of calcium signaling in Drosophila mushroom body neurons. Neurobiol Dis 41:147-159.

Testa-Silva G, Loebel A, Giugliano M, De Kock CPJ, Mansvelder HD, Meredith RM (2012) Hyperconnectivity and slow synapses during early development of medial prefrontal cortex in a mouse model for mental retardation and autism. Cereb Cortex 22:1333-1342.

Tian Y, Yang C, Shang S, Cai Y, Deng X, Zhang J, Shao F, Zhu D, Liu Y, Chen G, Liang J, Sun Q, Qu Z, Zhang C (2017) Loss of FMRP impaired hippocampal long-term plasticity and spatial learning in rats. Front Mol Neurosci 10:1-14

Zhang Y, Bonnan A, Bony G, Ferezou I, Pietropaolo S, Ginger M, Sans N, Rossier J, Oostra B, LeMasson G, Frick A (2014) Dendritic channelopathies contribute to neocortical and sensory hyperexcitability in Fmr1-/y mice. Nat Neurosci 17:1701-1709.

Zhu P, Li J, Zhang L, Liang Z, Tang B, Liao WP, Yi YH, Su T (2018) Development-related aberrations in Kv1.1 $\alpha$-subunit exert disruptive effects on bioelectrical activities of neurons in a mouse model of fragile $X$ syndrome. Prog Neuropsychopharmacol Biol Psychiatry $84: 140-151$. 